\title{
Advanced Obstetrical and Gynecological Ultrasound: Imaging with New Technologies
}

\author{
Ulrich Honemeyer, Asim Kurjak
}

\begin{abstract}
Since, ultrasound was introduced as diagnostic tool in obstetrics and gynecology by Professor lan Donald 6 decades ago, realtime imaging has become the most common sonographic technique used in obstetrics and gynecology. When uncertain findings on real-time gray scale during two-dimensional sonography require further evaluation, advanced techniques are often necessary. Such advanced techniques include color and power Doppler, three- and four-dimensional ultrasound and techniques of volume manipulation (rendering), such as surface and maximum mode, magic cut, volume calculation (VOCAL), NICHE mode, and -as latest innovation, HD flow (Doppler) and HD life surface rendering. The authors would like to illustrate by means of a series of images and case presentations, how these new diagnostic tools find their clinical application in the daily routine of care in obstetrics and gynecology.
\end{abstract}

Keywords: 3D ultrasound, 4D ultrasound, Volume rendering, HD flow, HD life.

How to cite this article: Honemeyer $U$, Kurjak A. Advanced Obstetrical and Gynecological Ultrasound: Imaging with New Technologies. Donald School J Ultrasound Obstet Gynecol 2013;7(1):51-65.

\section{Source of support Nil}

Conflict of interest: None declared

\section{INTRODUCTION}

Three-dimensional (3D) sonography functions as twodimensional (2D) static display of a 3D data set. To acquire and render images, special probes and software are necessary. 3D technology can reduce scanning time since, the acquired volume data set of the fetus in obstetrical ultrasound, and the pelvis in gynecologic ultrasound, can be explored and evaluated without the patient. 3D surface rendering with $3 \mathrm{D}$ sonography demonstrates much clearer those abnormalities of the fetus which had been detected with 2D sonography. Splendid examples for remote evaluation of 3D volumes are facial abnormalities, neural tube defects, and fetal central nervous system (CNS) anomalies.

Four-dimensional (4D) sonography, also known as dynamic 3D sonography, stands for visualization of 3D images in real-time. 4D ultrasound is used to study fetal movement, behavioral states and the fetal heart.

Color Doppler, power Doppler and HD flow represent sonographic techniques to visualize (blood) flow. While color D oppler allows differentiation of flow direction, power
Doppler does not provide this information, how ever is able to detect slow flow in smaller blood vessels, and proves valuable in depicting tumor-neoangiogenesis with low resistance indices. HD flow refers to a recently introduced combination of color and power Doppler, by adding the information of flow direction to the advantages of power Doppler.

All high end ultrasound machines come equipped with rendering software which includes several programs to enhance 3D findings and make them more obvious. Surface rendering-effective whenever, a fluid layer covers the targeted surface-is a powerful instrument in visualization of fetal facial defects, but also helpful in showing intracystic proliferations of ovarian tumors, and improving diagnostic evidence in saline infusion sonohysterography (SISH). $M$ aximum mode, suppressing echoes of lower intensity, is excellent in imaging of skeletal abnormalities. 3D cine rotation enables rotation of a rendered object in $X$ - or $Y$ axis up to $360^{\circ}$, augmenting the spatial perception of the object. Magic cut puts an electronic scalpel into the hand of the ultrasound operator allowing dissection of whichever part of the volume. NICHE mode lets the sonographer move a transparent wedge along the $X-, Y$ - or Z-axis into the volume, thus providing valuable information of the interior of the volume. VOCAL software calculates an accurate volume of not only spherical, but also irregular shaped objects. Inversion mode emphasizes areas of low or absent echogenicity in a volume and plays an important role in assisted human reproduction by visualizing the effects of ovarian stimulation. HD live software gives the operator a virtual light source to enhance 3D and 4D visual impression, by introducing light and shadow effects into the image and creating al most fetoscopic-like images.

\section{Application of Advanced Ultrasound in Gynecology}

The goal of ovarian cancer screening is to detect the disease as long as it is confined to the ovary (stage I) and thereby prolong survival. U nfortunately, most ovarian cancer, at its earliest recognizable stage, is probably not confined to the ovary any more (stage II and more). ${ }^{1}$

The greatest concern is indicated with adnexal masses which have a complex internal structure, and solid components. $^{2}$ 
Tumor vasculature resulting from malignant neoangiogenesis with low resistance to flow $(\mathrm{RI}<0.42)$ represents another important diagnostic criterion and is accessible by color-, power- and HD flow Doppler. ${ }^{3}$

Images of Benign and

Malignant Ovarian Tumors (Figs 1 to 14 )

U terine pathology often presents as the cause of menstrual irregularities, lower abdominal pain and infertility. ${ }^{4}$ A dvanced ultrasound as a noninvasive method contributes to early diagnosis of such causes and enables appropriate decisions for clinical management. Minimal invasive diagnostic ultrasound in the form of SISH can produce almost hysteroscopy-like images and gives clear directions to the surgeon regarding options of operative hysteroscopy.

Images of Uterine Anomalies and

SISH (Figs 15 to 44 )

\section{Application of Advanced Ultrasound in Obstetrics}

Sonographic assessment during first trimester targets ovulation, early and advanced embryonic stage, and early fetus. It is obvious that diagnosis of abnormal early pregnancy, pregnancy failure and fetal abnormalities should be established as early as possible to enable timely decisions

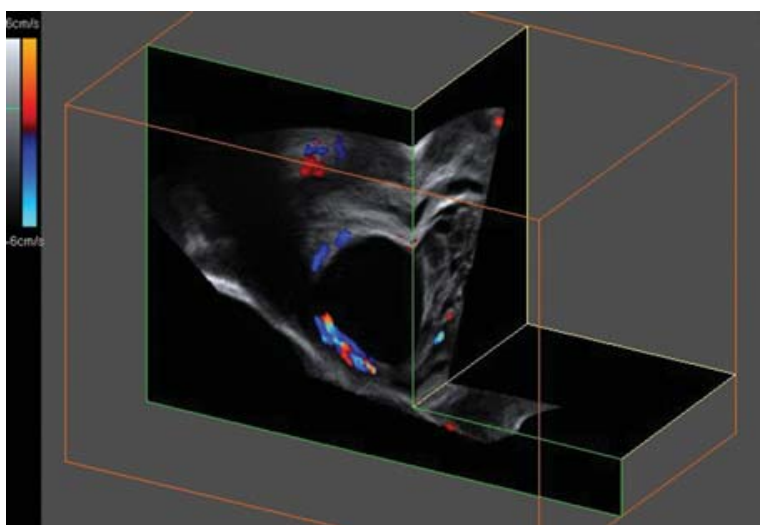

Fig. 1: Corpus luteum in 3D color Doppler mode on day 14 of menstrual cycle

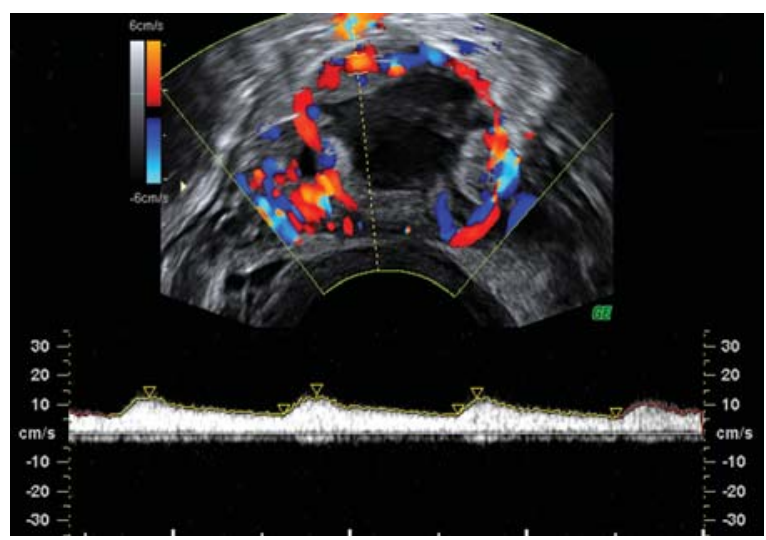

Fig. 2: Corpus luteum, pulsed wave Doppler with characteristic low resistance-to-flow
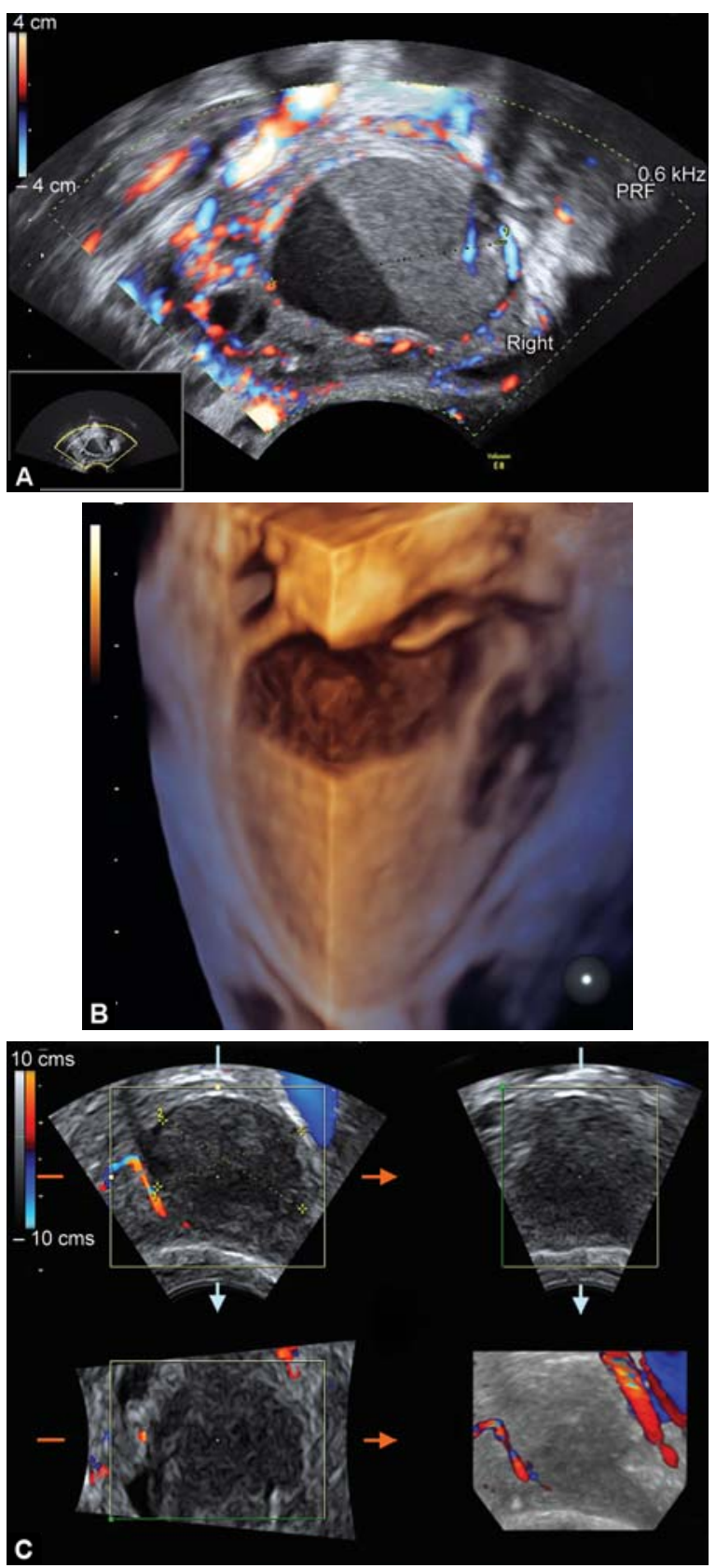

Figs 3 A to C: Endometriosis ovarii in different stages: (A) Early stage with sedimentation gray scale and HD flow Doppler; (B) surface rendered magic cut, (C) follow-up after 10 months

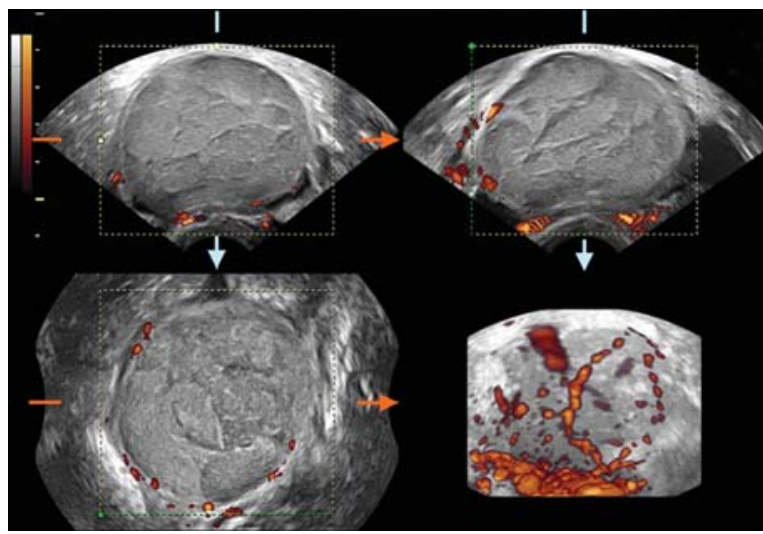

Fig. 4: Hemorrhagic ovarian cyst early stage multiplanar power Doppler 


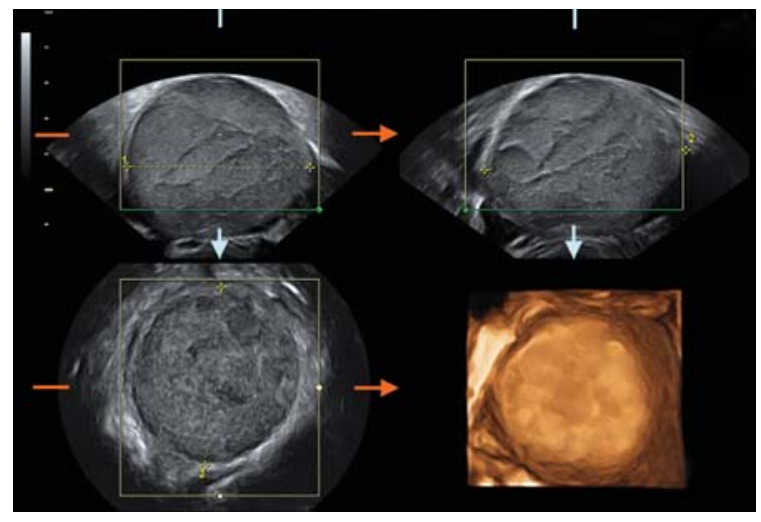

Fig. 5: Hemorrhagic ovarian cyst early stage multiplanar surface rendered

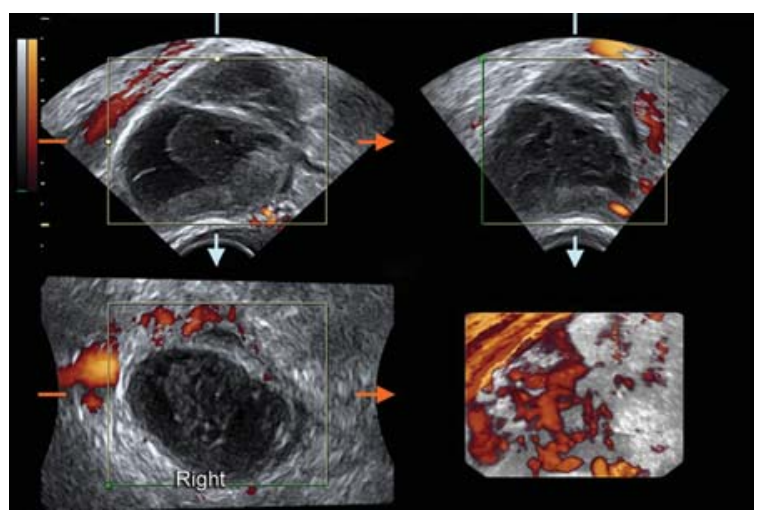

Fig. 6: Hemorrhagic cyst fresh with fibrin strands power Doppler

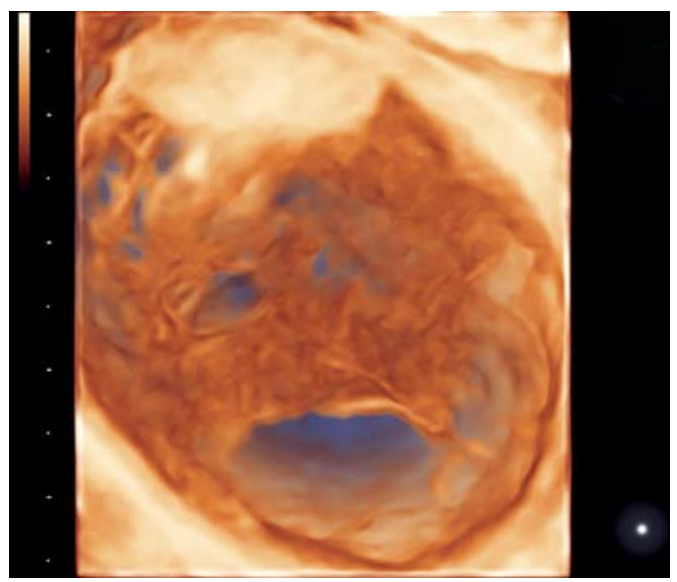

Fig. 7: Hemorrhagic cyst fresh high gain surface rendered

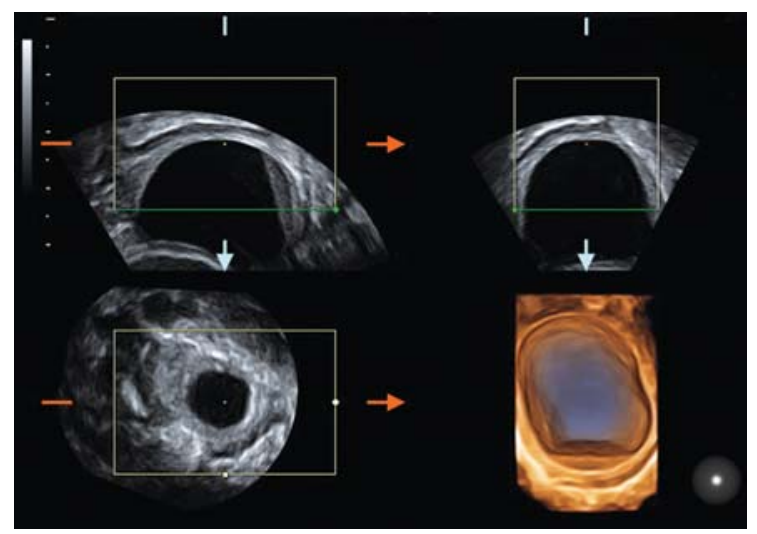

Fig. 8: Hemorrhagic ovarian cyst with sedimentation

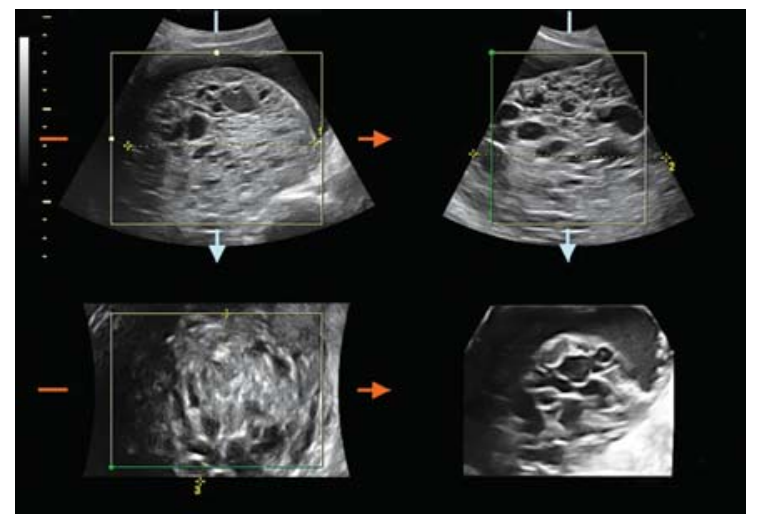

Fig. 9: Malignant ovarian mass 3D multiplanar

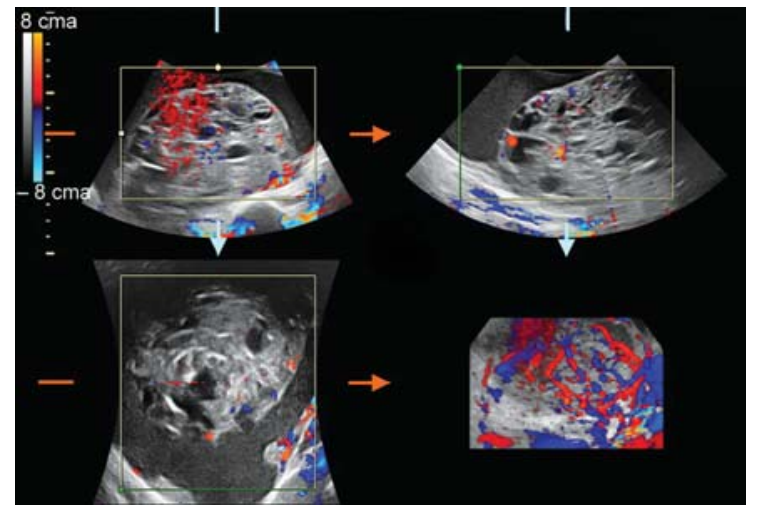

Fig. 10: Malignant ovarian mass multiplanar color Doppler, tumor neoangiogenesis

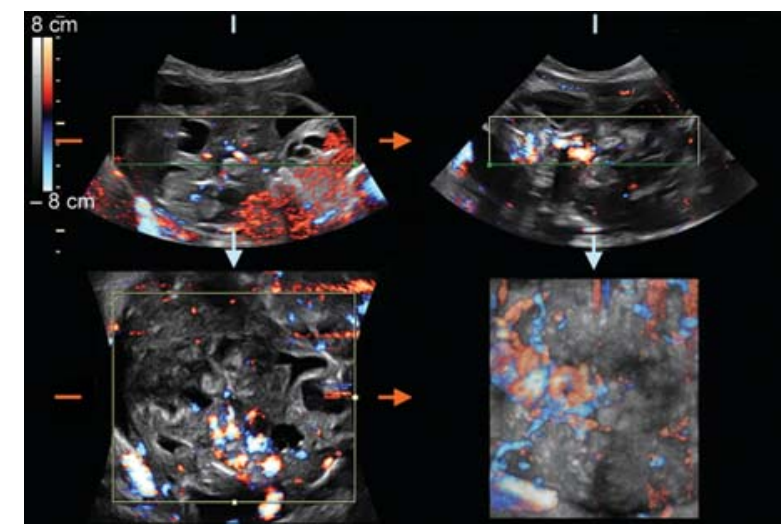

Fig. 11: Malignant ovarian tumor low resistance index (RI) to flow

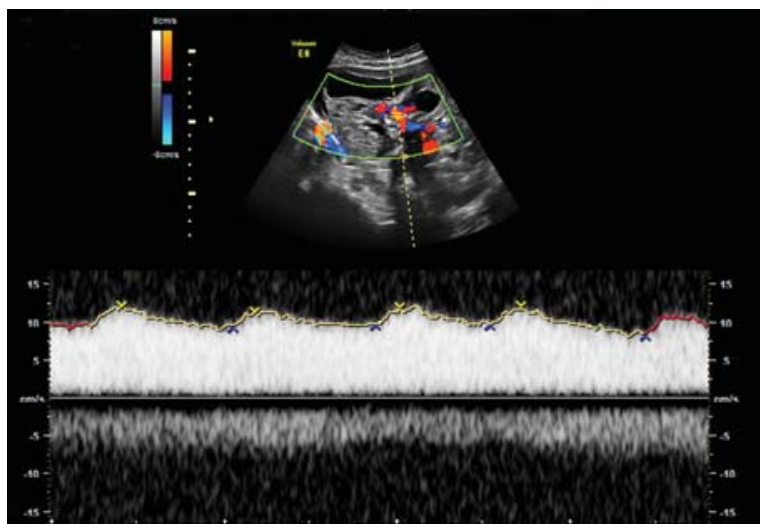

Fig. 12: Malignant ovarian tumor low RI in pulsed wave Doppler 


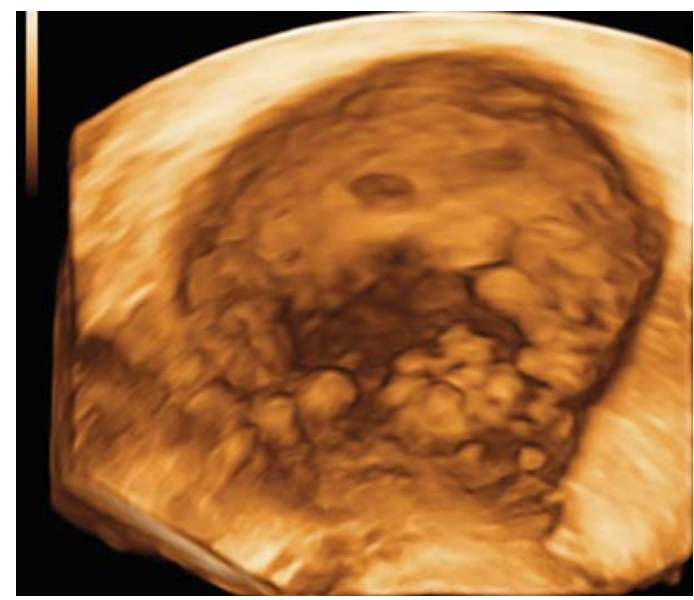

Fig. 13: Right ovarian mass with intracystic proliferations, 3D surface rendered

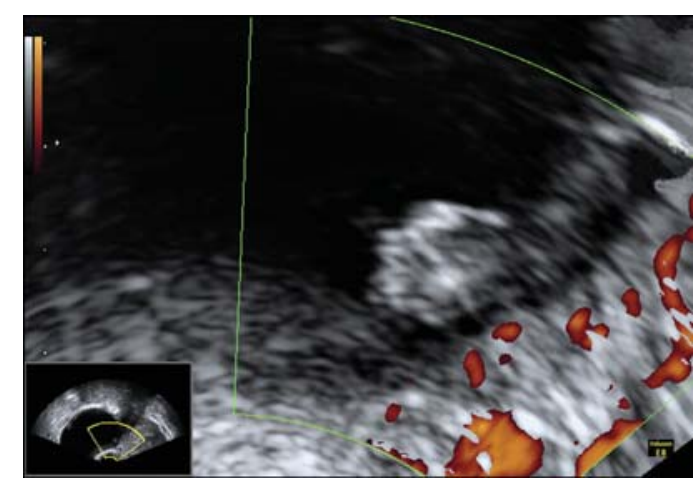

Fig. 14: Right ovarian mass, magnified intracystic proliferation, power Doppler

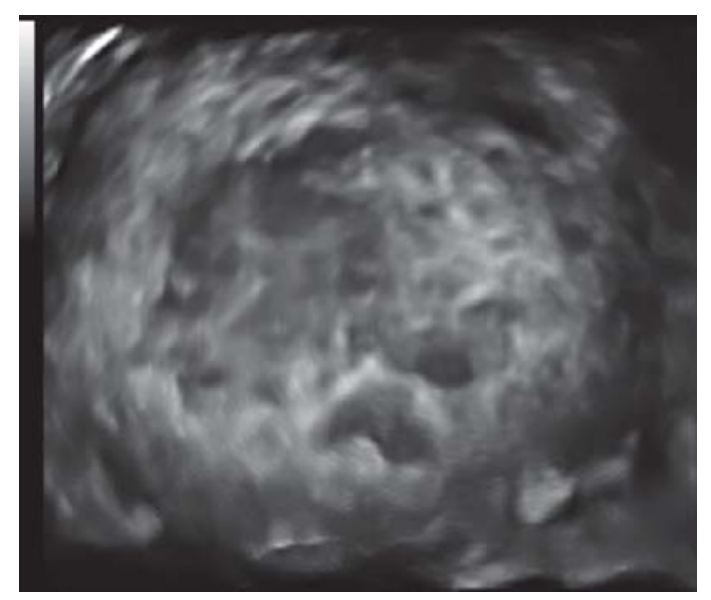

Fig. 15: Chorioncarcinoma 3D slice of uterus

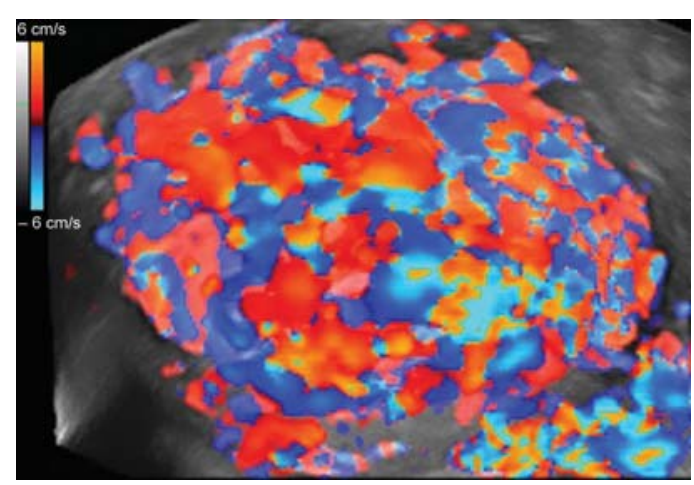

Fig. 16: Chorioncarcinoma 3D CD

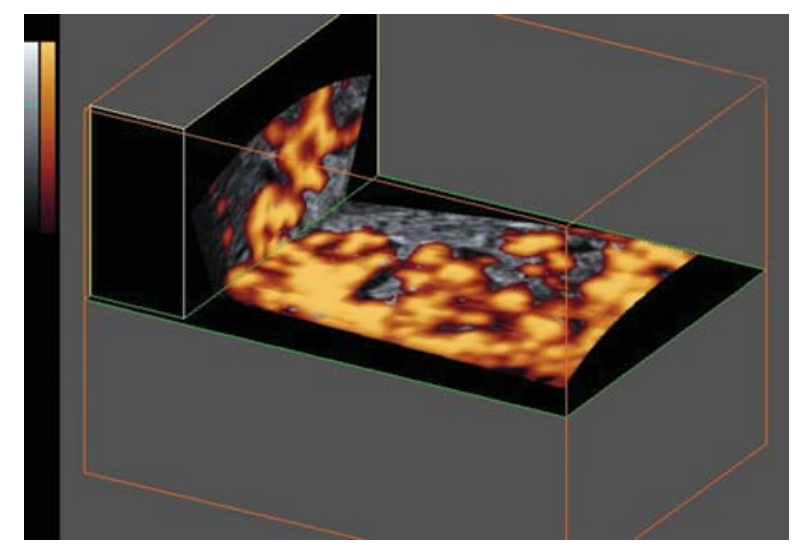

Fig. 17: Chorioncarcinoma 3D PD magnified niche

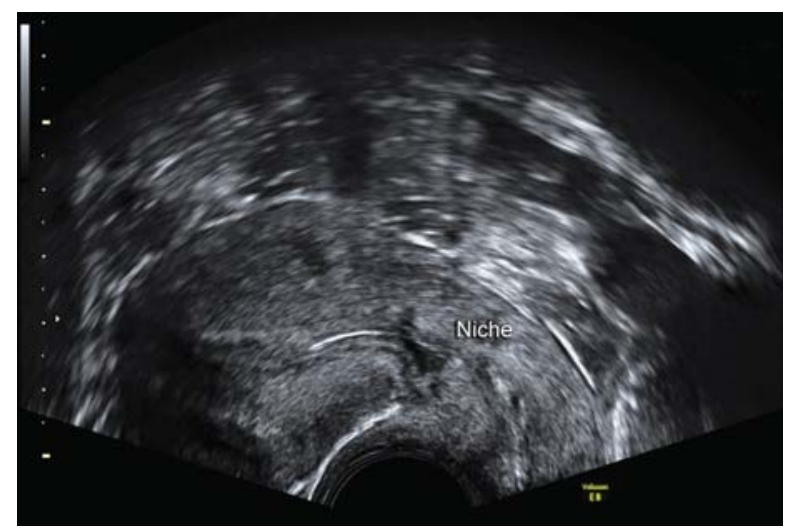

Fig. 18: Niche in the anterior lower uterine segment after LSCS

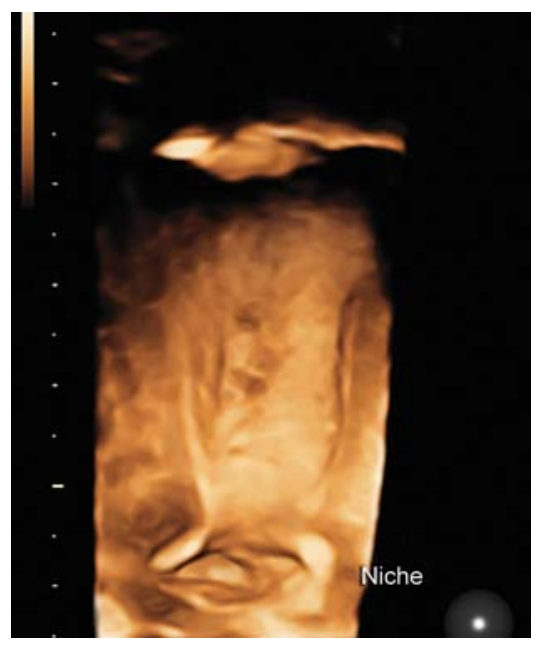

Fig. 19: Niche after LSCS, 3D surface rendered

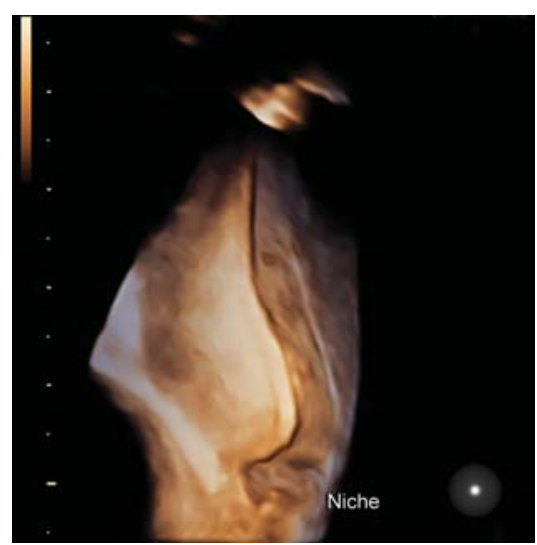

Fig. 20: Niche after LSCS 


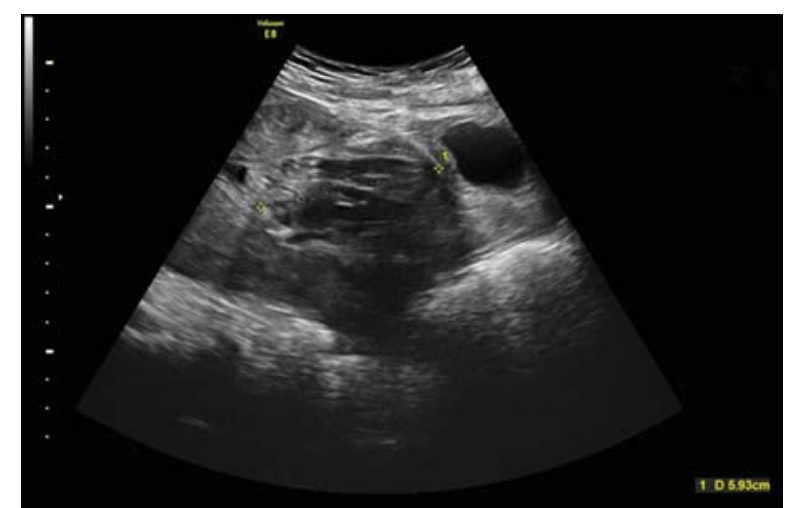

Fig. 21: Ruptured LSCS scar after vacuum delivery

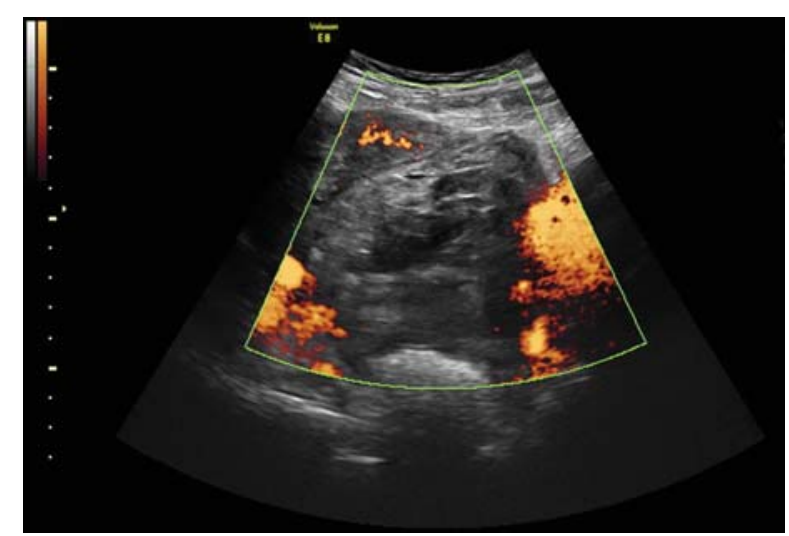

Fig. 22: Ruptured LSCS scar after vacuum delivery, avascular heterogenic mass coagula

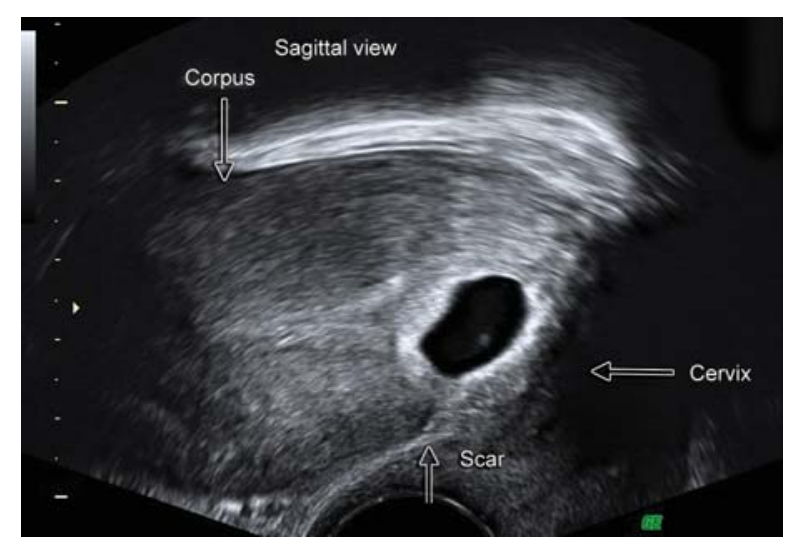

Fig. 23: LSCS scar ectopic pregnancy overview B mode

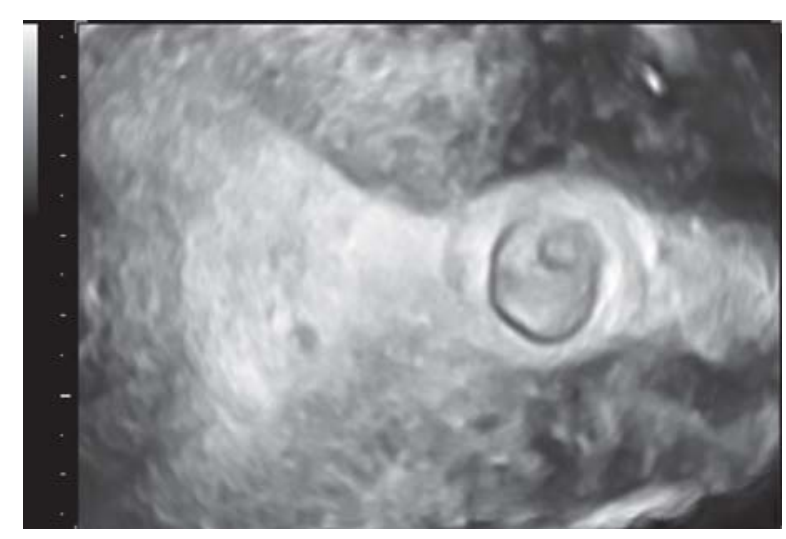

Fig. 24: LSCS scar ectopic pregnancy 3D glass body

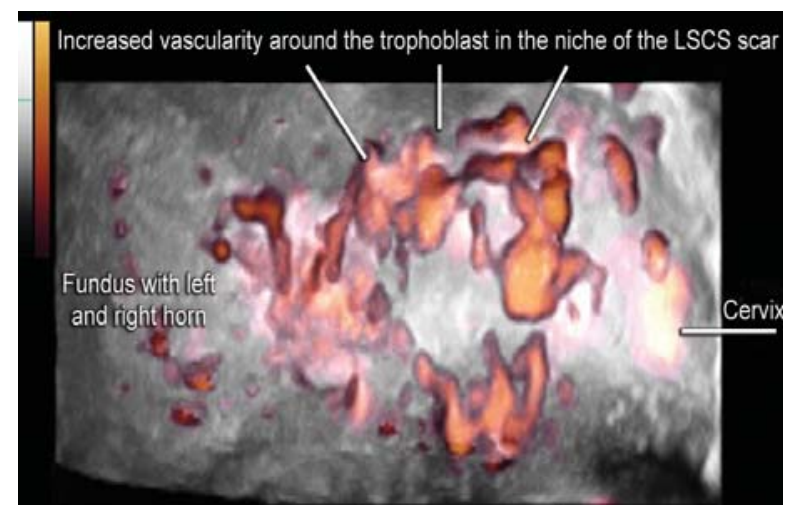

Fig. 25: LSCS scar ectopic pregnancy 3D PD ROT extract

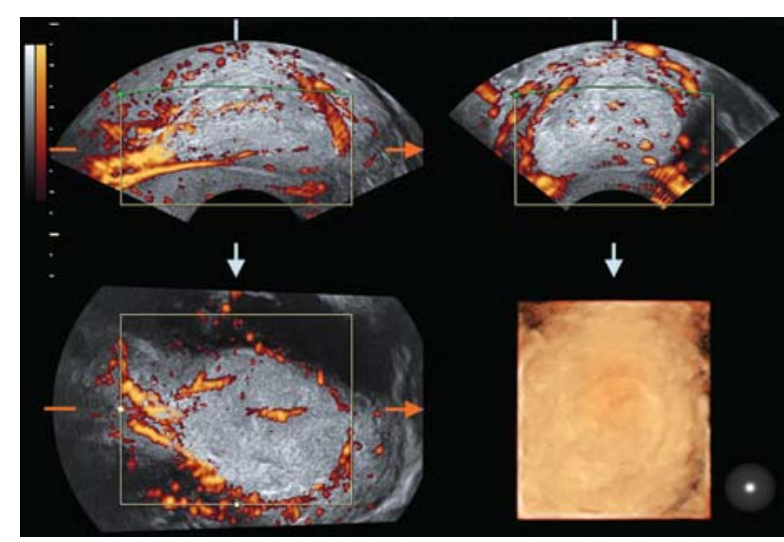

Fig. 26: Pedunculated uterine fibroid in statu nascendi

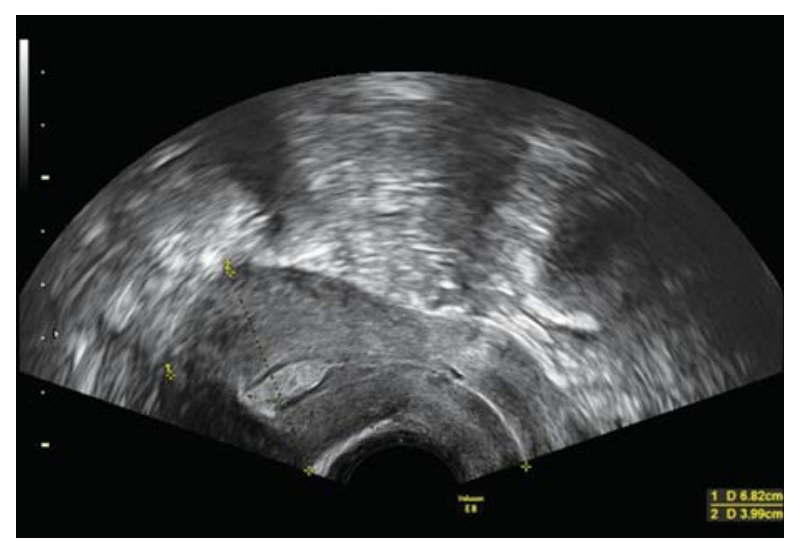

Fig. 27: SISH polyp in B-mode

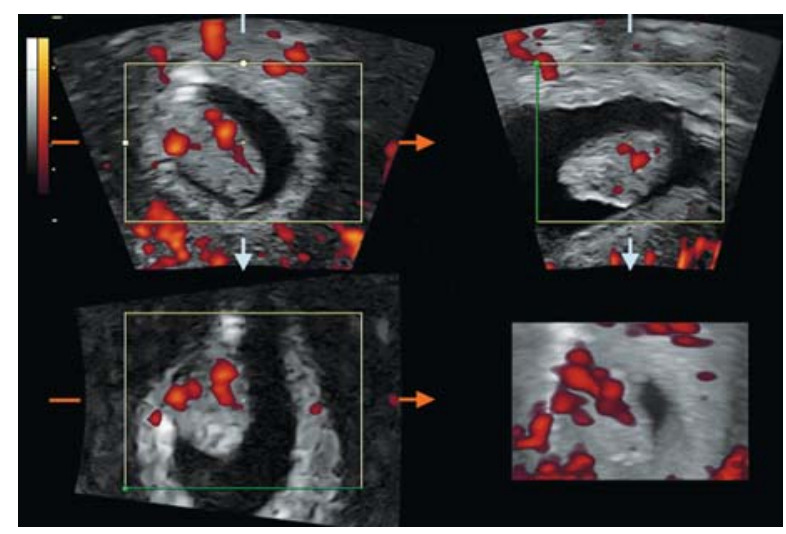

Fig. 28: SISH polyp glass body power Doppler 


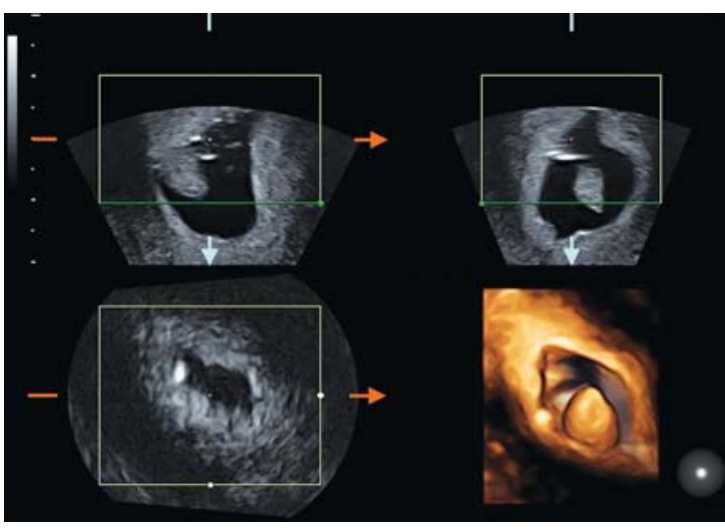

Fig. 29: SISH polyp 3D surface rendering

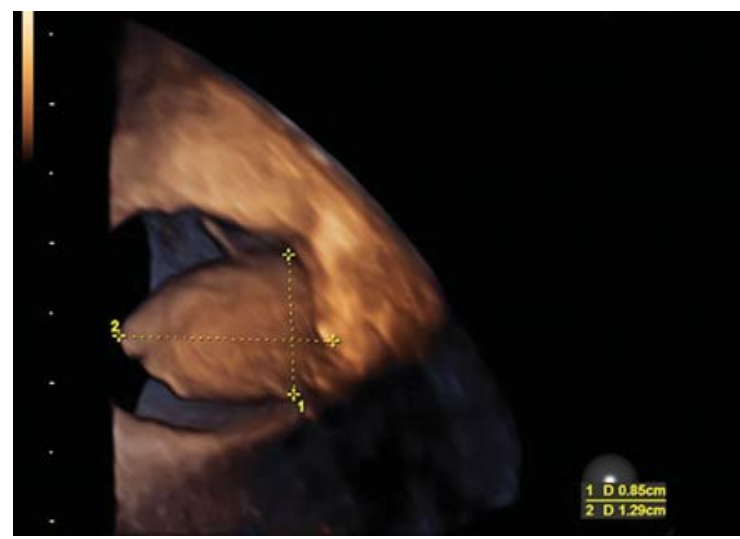

Fig. 30: SISH polyp 3D surface rendered image

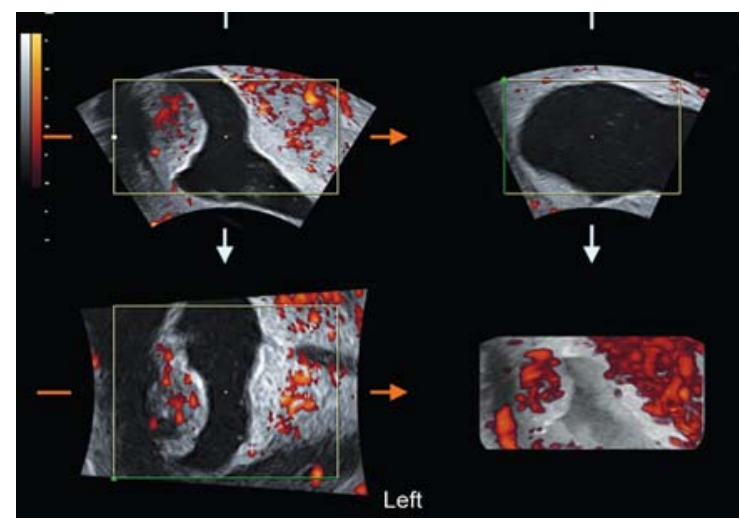

Fig. 31: SISH submucous fibroid multiplanar image

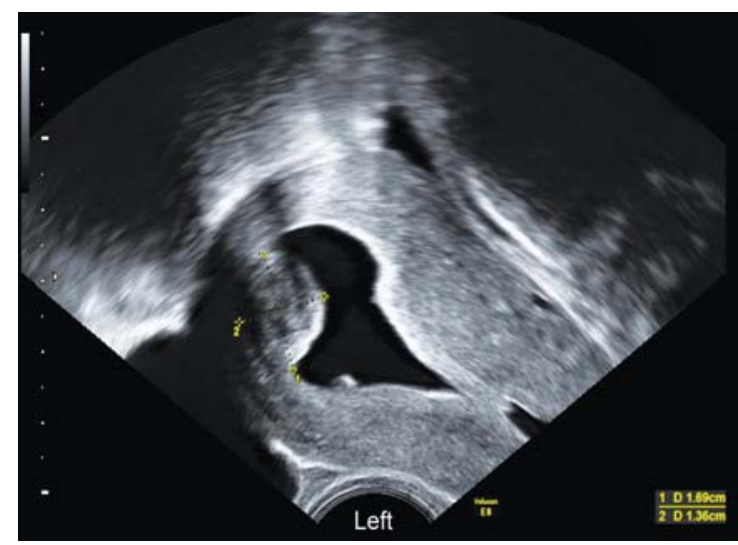

Fig. 32: SISH submucous fibroid after saline infusion

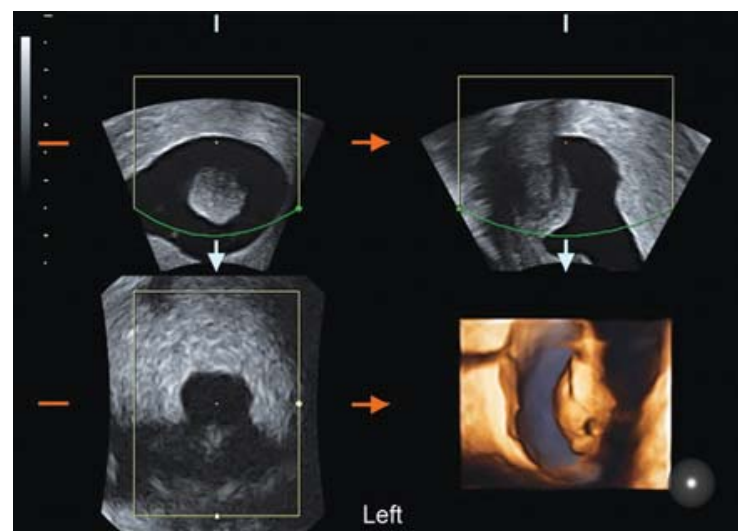

Fig. 33: SISH submucous fibroid 3D surface rendered

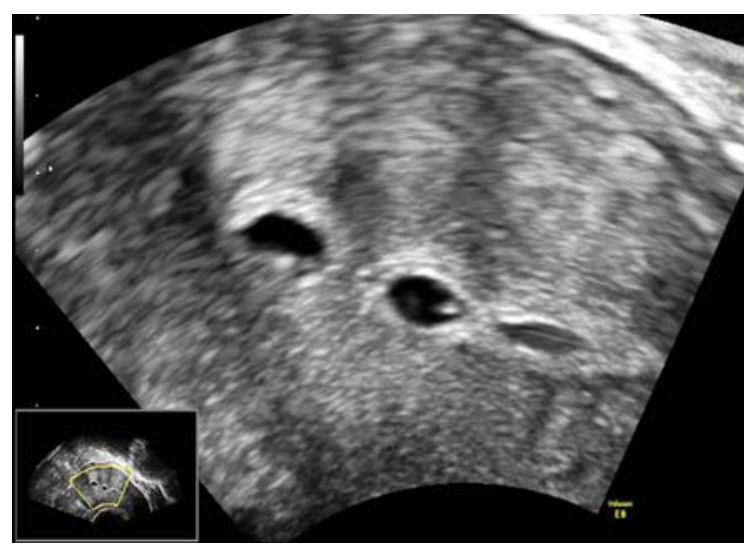

Fig. 34: SISH uterine synechia

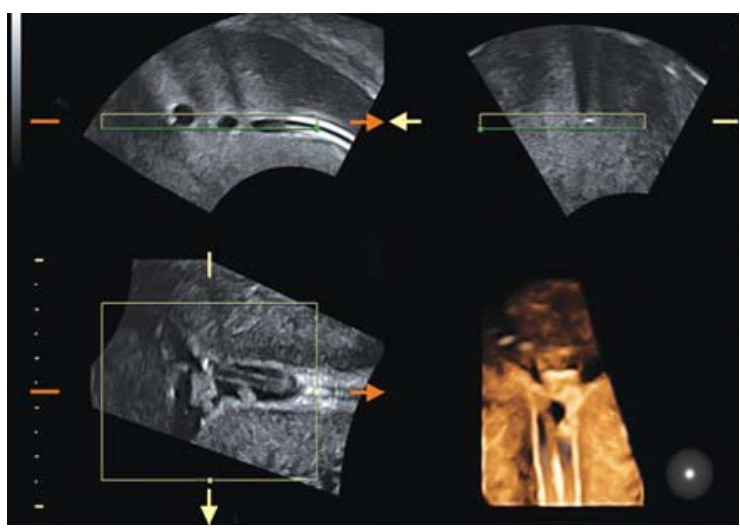

Fig. 35: SISH synechia 3D multiplanar image

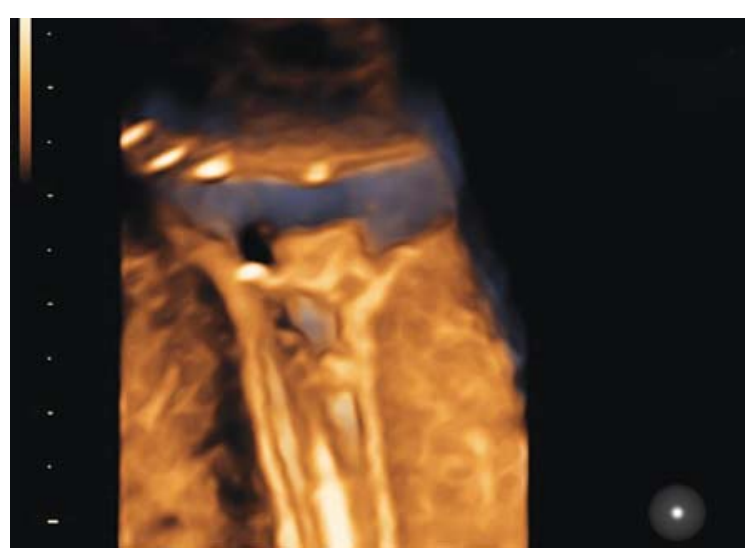

Fig. 36: SISH synechia 3D surface rendered image 


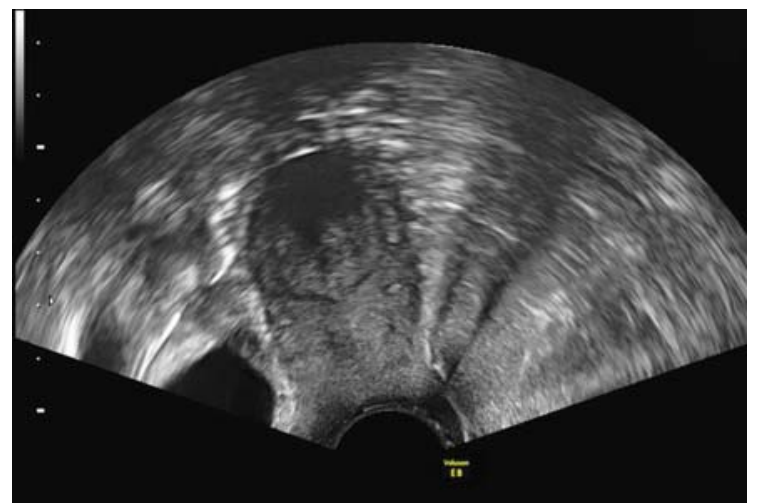

Fig. 37: SISH uterine septum gray scale

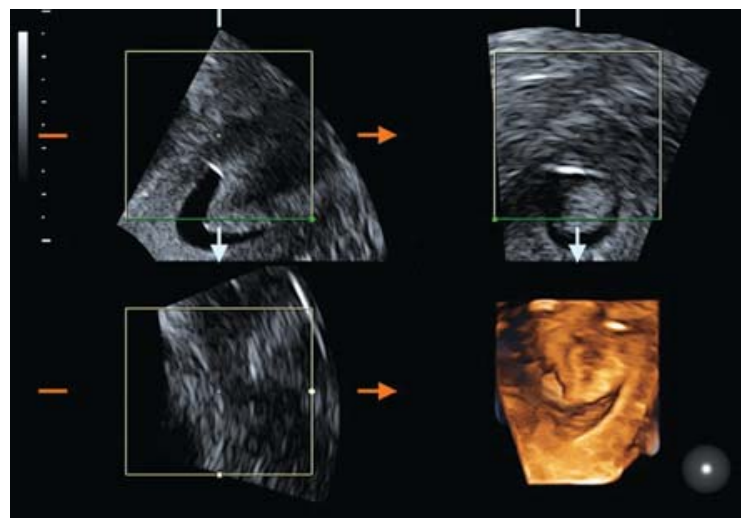

Fig. 38: SISH uterine septum 3D multiplanar

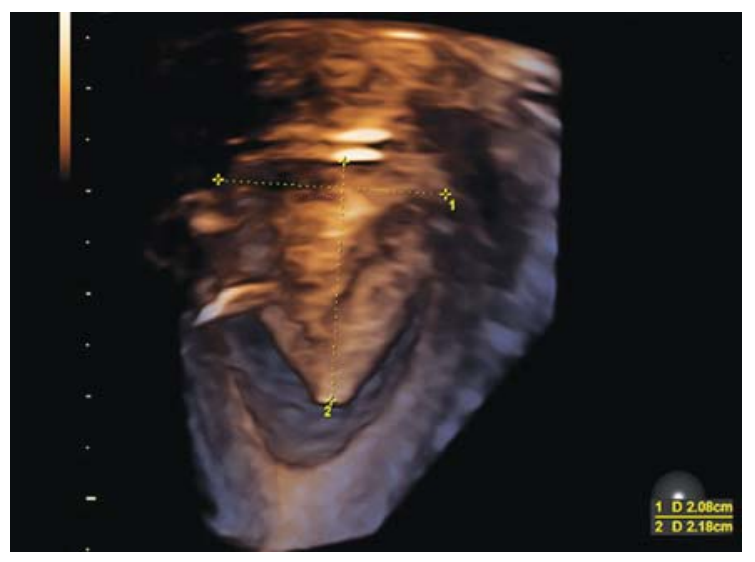

Fig. 39: SISH uterine septum 3D surface rendered

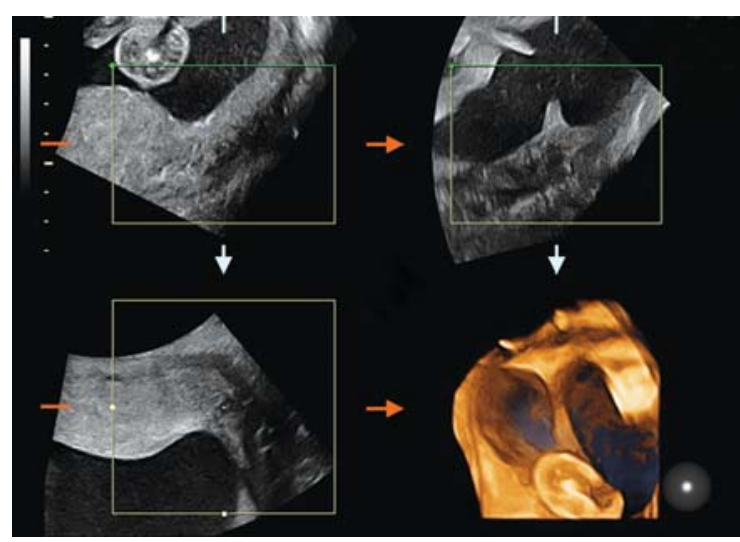

Fig. 40: Uterine septum in pregnancy 21 weeks 5 days

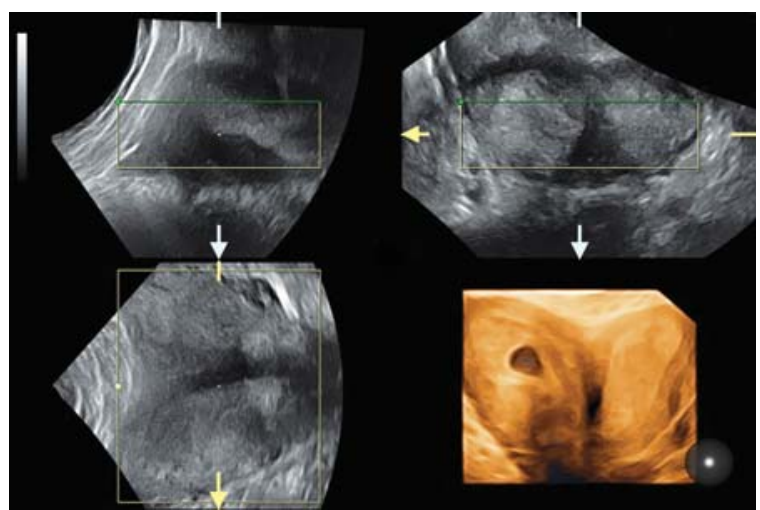

Fig. 41: Uterus bicornis with pregnancy multiplanar

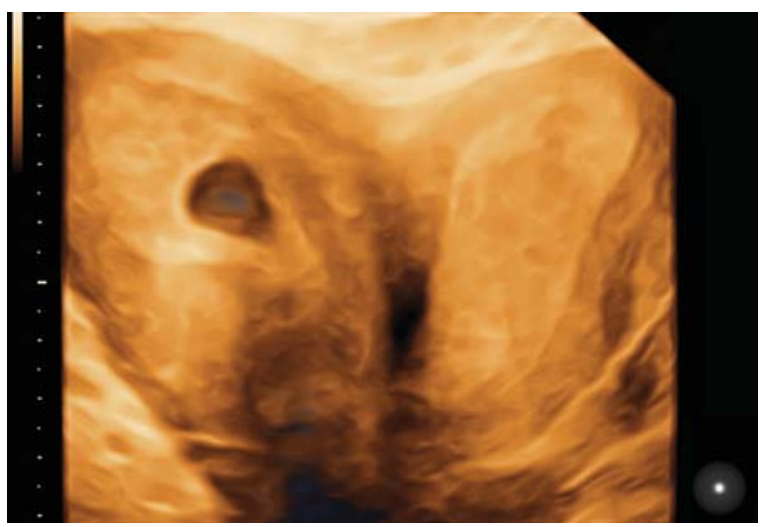

Fig. 42: Uterus bicornis with pregnancy 3D surface rendered image

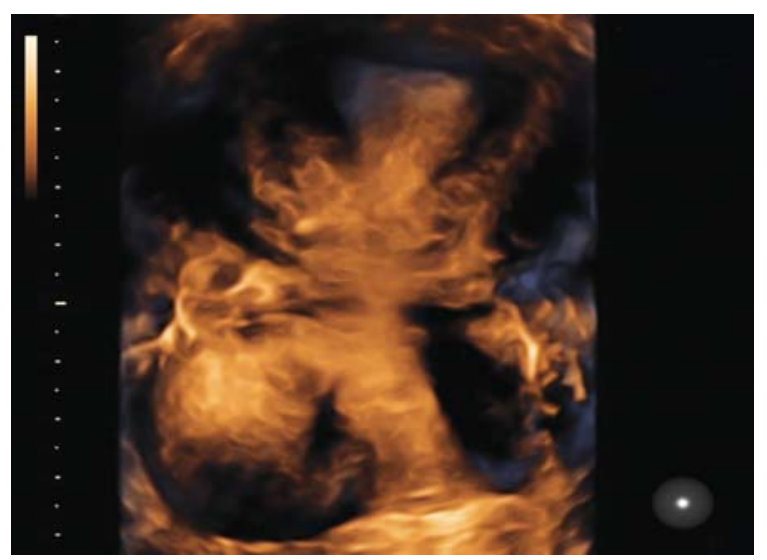

Fig. 43: Uterus with intraligamentary fibroid 3D surface rendered

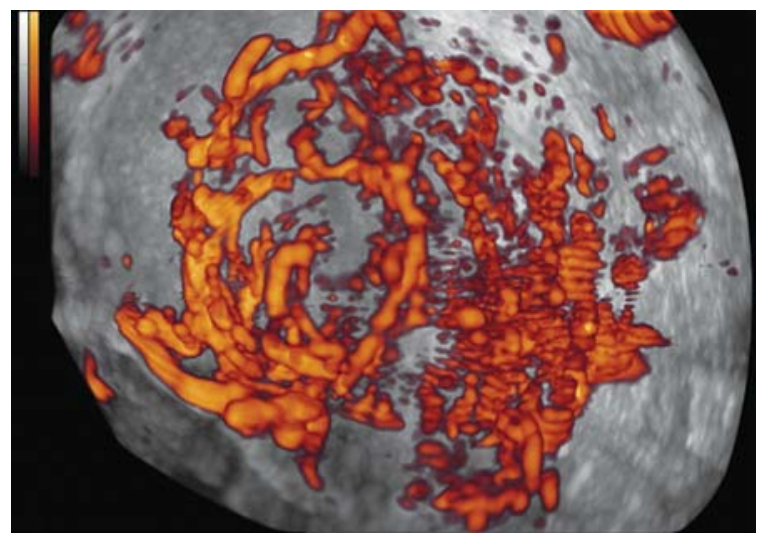

Fig. 44: Uterus with intraligamentary fibroid power Doppler 
about management. The introduction of 3D, real-time 3D (4D), color- and power Doppler, and their attachment to transvaginal scanning has boosted our knowledge of early pregnancy and its pathology ever more. M eanwhile, first trimester ul trasound differentiation of abnormal from normal pregnancy development directs the management of early pregnancy.

Images of Normal and Abnormal early

Pregnancy ( $F$ igs 45 to 60 )

Images of Pregnancy Complications (Figs 61 to 72)

Fetal face: A round the 13th week, after the 'puzzle' of the human face-with the philtrum as center point of the

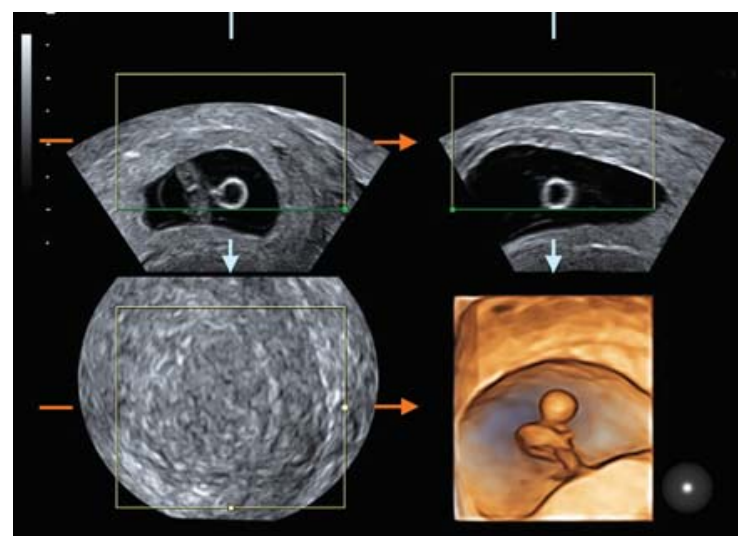

Fig. 45: Embryo at 7w0d, multiplanar image

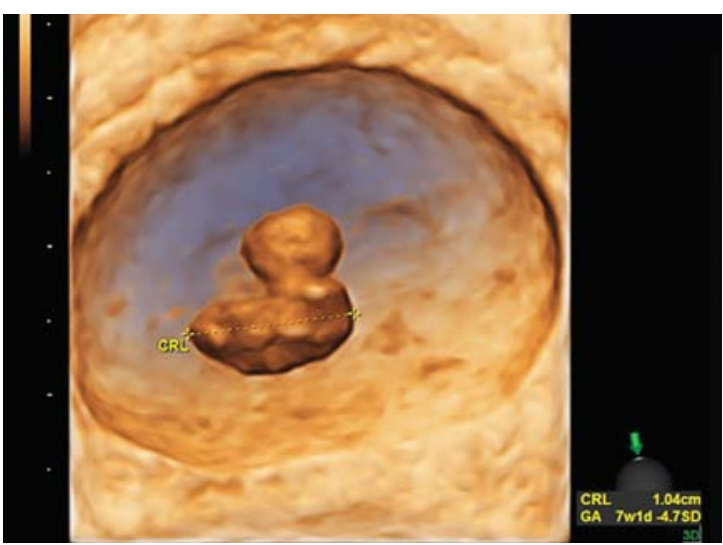

Fig. 46: 7w1d early embryo in HDLive 3D surface rendering

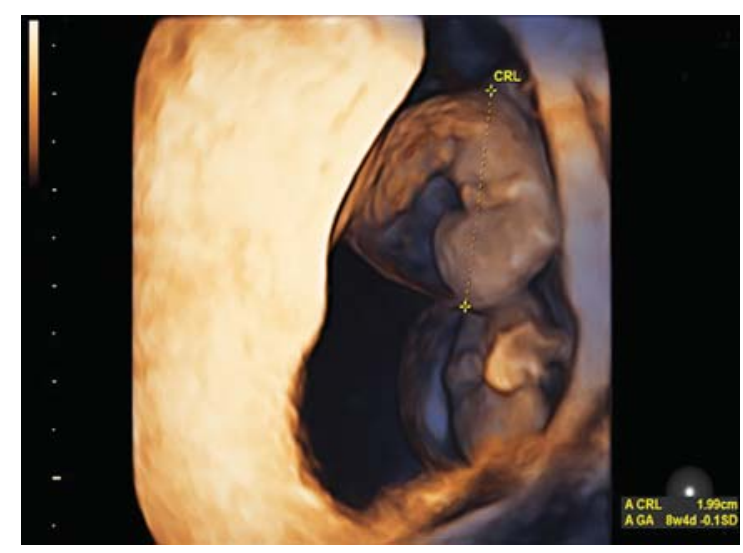

Fig. 47: Monochorionic (MC) twins at $8 w 5 d$, 3D surface rendering arrangement-has finally been set together, the anatomy of the face is developed and can be analyzed for diagnostic purpose. At present, the interconnection between development of the face, craniofacial skeleton and brain is undisputed. ${ }^{5-7}$

Images of the Fetal Face (Figs 73 to 86 )

4D ultrasound in second and third trimester: B eginning with vermicular and predominantly gross movements of the embryo at 7 to 8 weeks, already the behavior of the early fetus at 10 weeks includes more and more complex

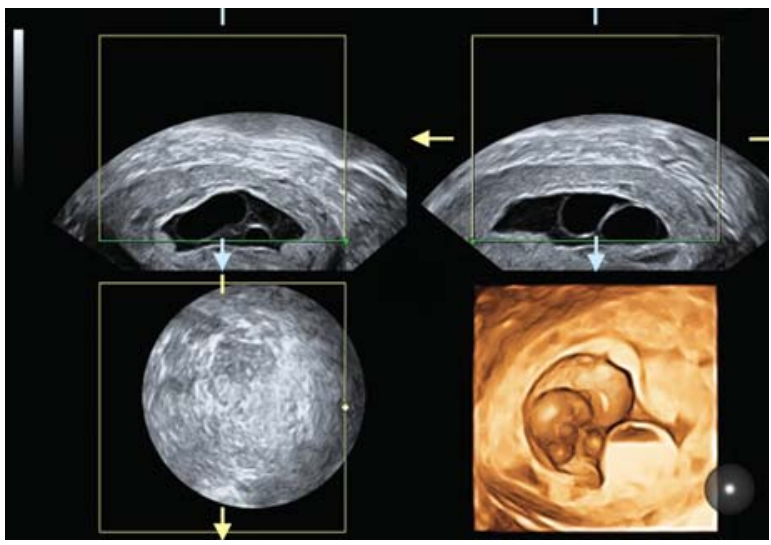

Fig. 48: Molar pregnancy 9w5d multiplanar

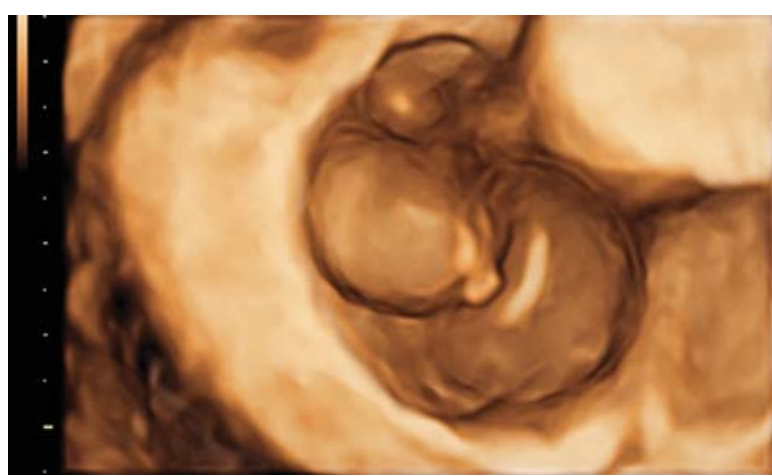

Fig. 49: Molar pregnancy 9w5d, 3D surface rendered

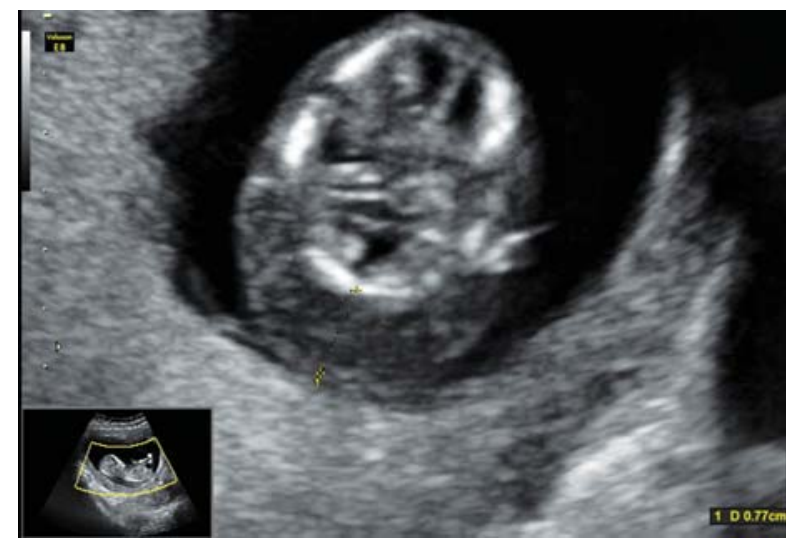

Fig. 50: Nuchal translucency (NT) $7.4 \mathrm{~mm}$, coronal view with nuchal edema 


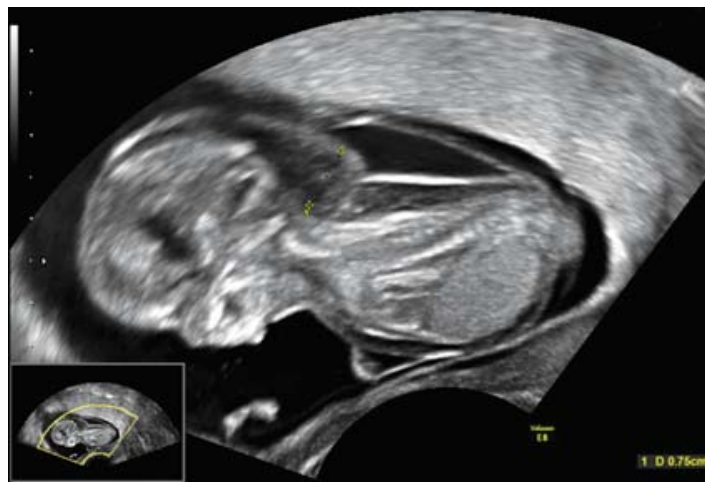

Fig. 51: NT $7.4 \mathrm{~mm}$, fetal long axis lateral view

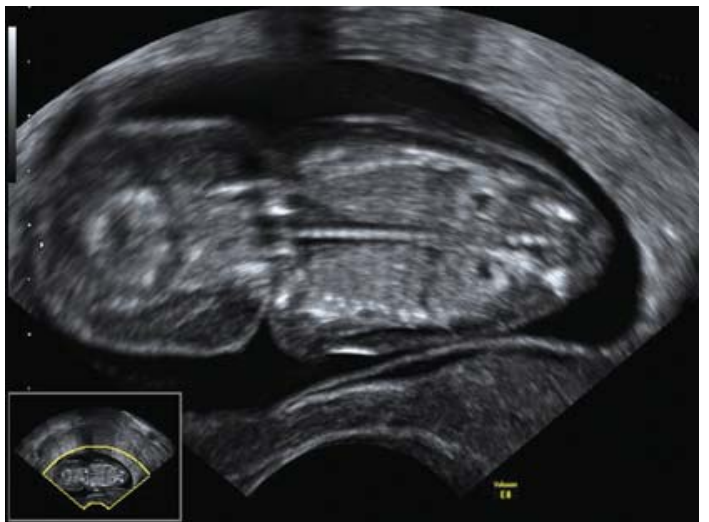

Fig. 52: NT $7.4 \mathrm{~mm}$, coronal view with nuchal edema

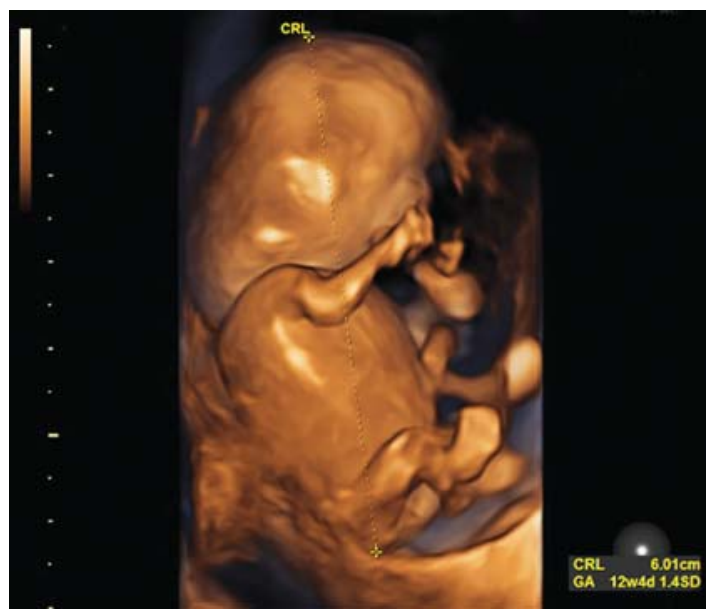

Fig. 53: NT $7.4 \mathrm{~mm}$, 3D surface rendered image of the fetus

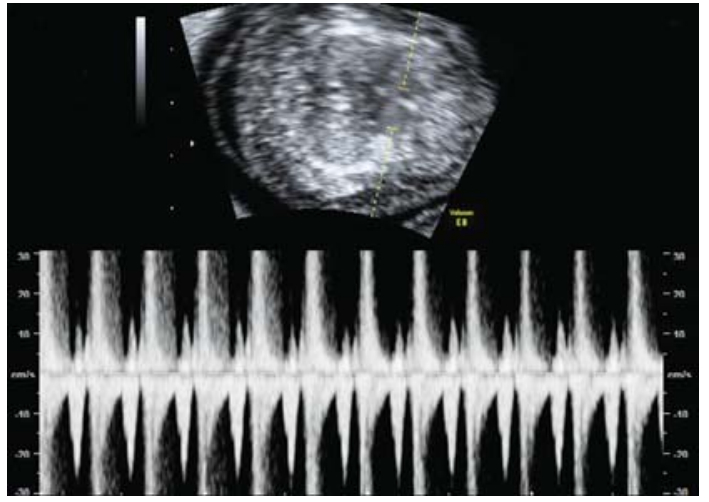

Fig. 54: NT $7.4 \mathrm{~mm}$, massive turbulent regurgitation over mitral valve

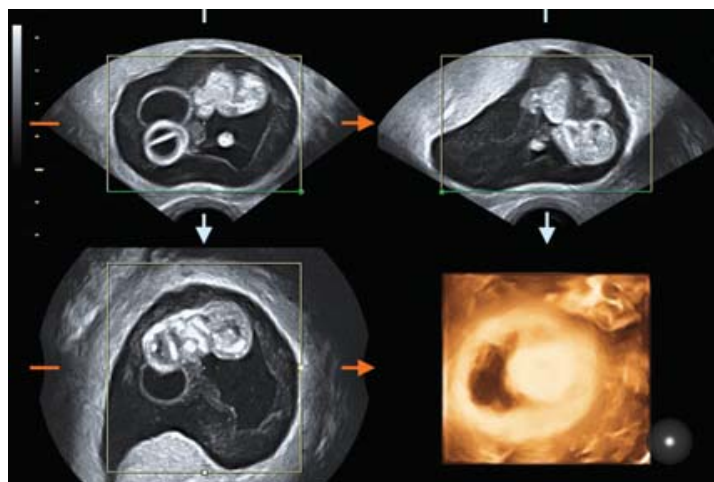

Fig. 55: Body stalk syndrome, 11w6d, multiplanar 3D with high gain

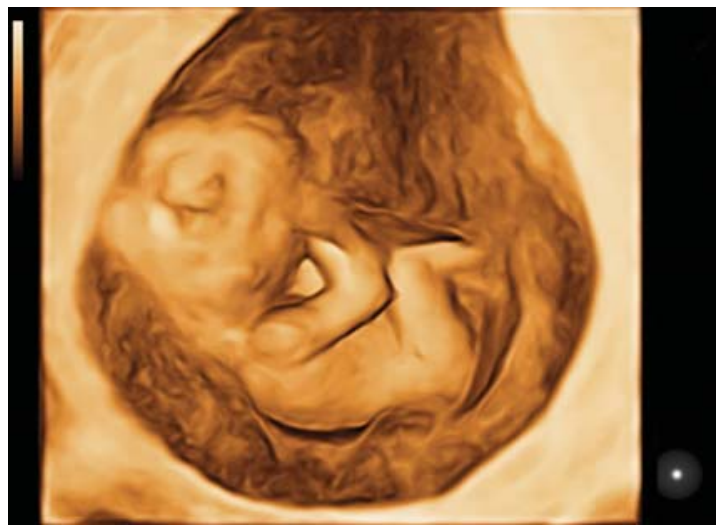

Fig. 56: Body stalk 11w6d surface rendered high gain

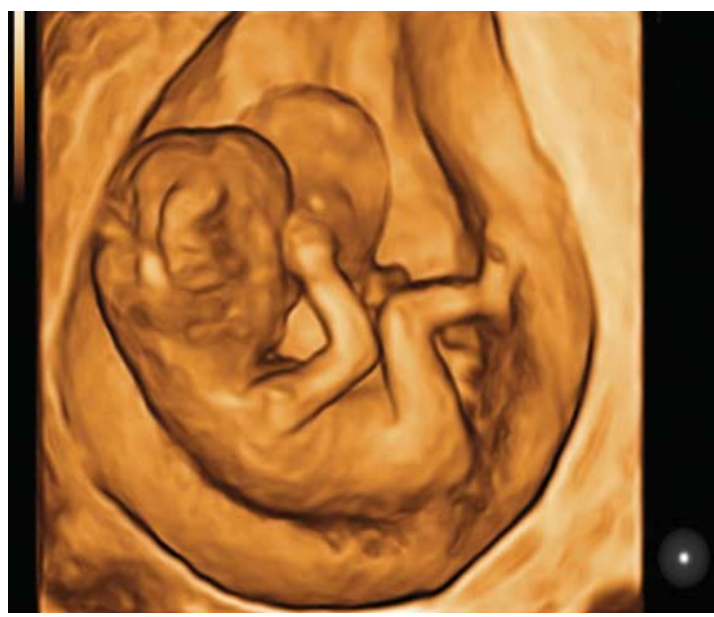

Fig. 57: Body stalk 11w6d surface rendered low gain

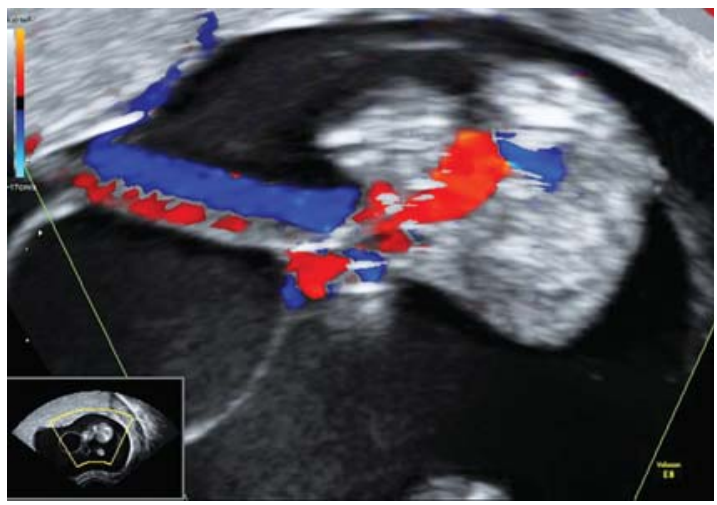

Fig. 58: Body stalk 11w6d color Doppler short umbilical cord 


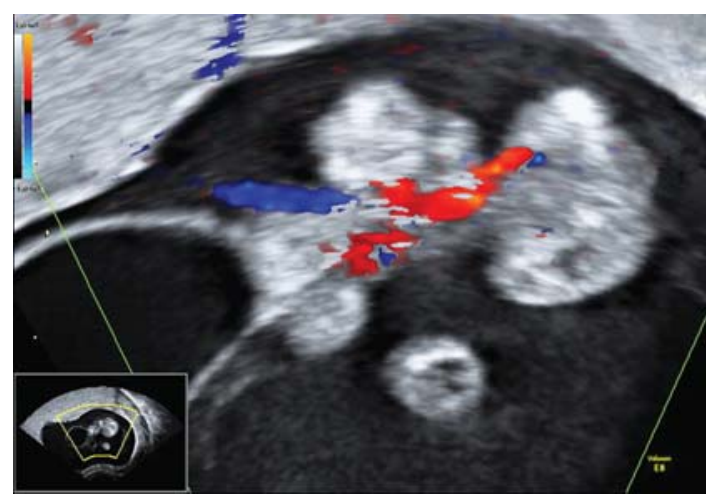

Fig. 59: Body stalk 11w6d gastroschisis

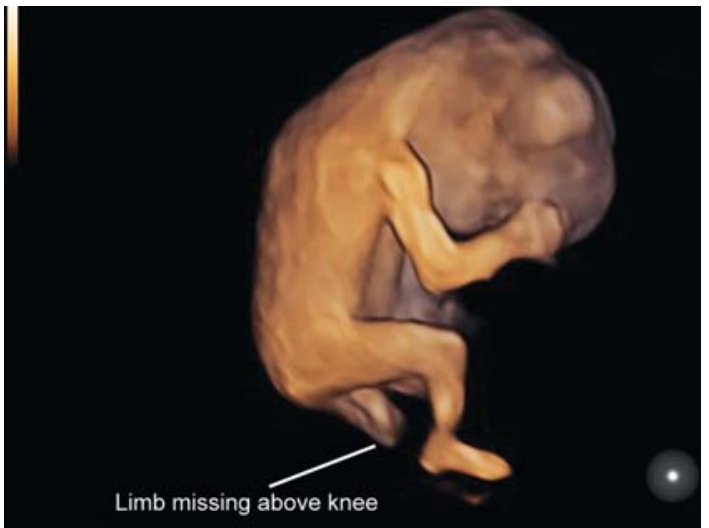

Fig. 60: Body stalk 11w6d fetus magic cut, limb defect (lower leg)

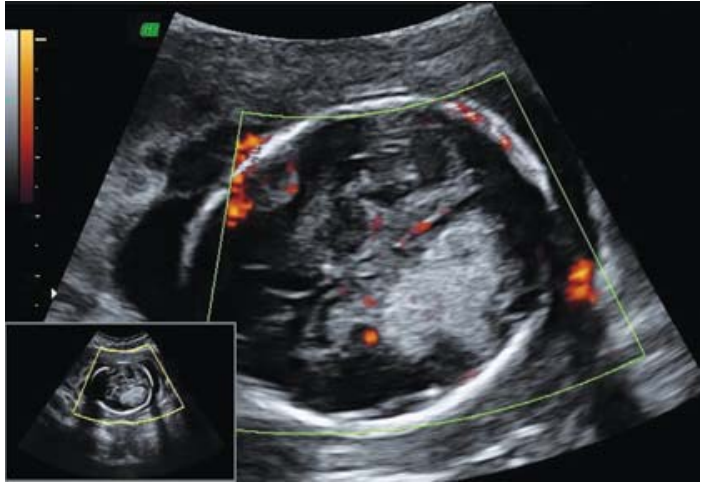

Fig. 61: Brain tumor 22 weeks, B-mode power Doppler

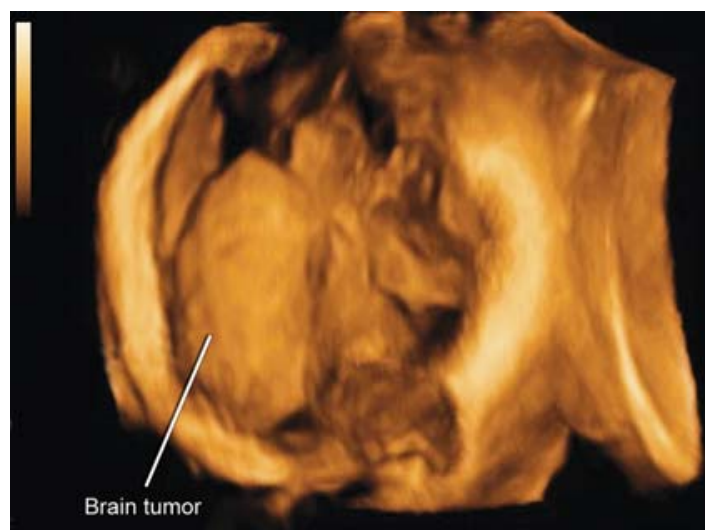

Fig. 62: Brain tumor 22 weeks, 3D surface rendered, magic cut

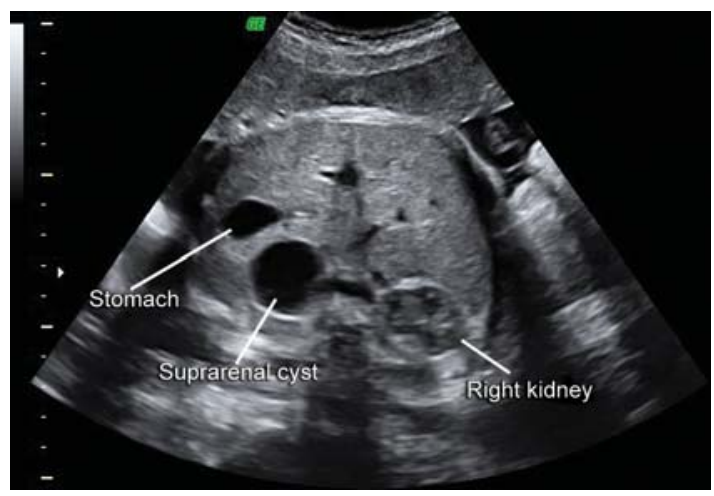

Fig. 63: Adrenal hemorrhage 38w6d, B-mode, abdomen transverse

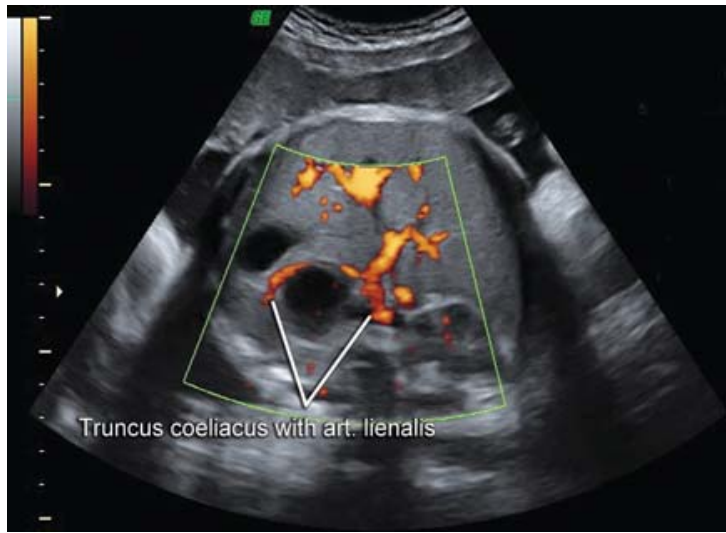

Fig. 64: Adrenal hemorrhage, B-mode power Doppler transverse view

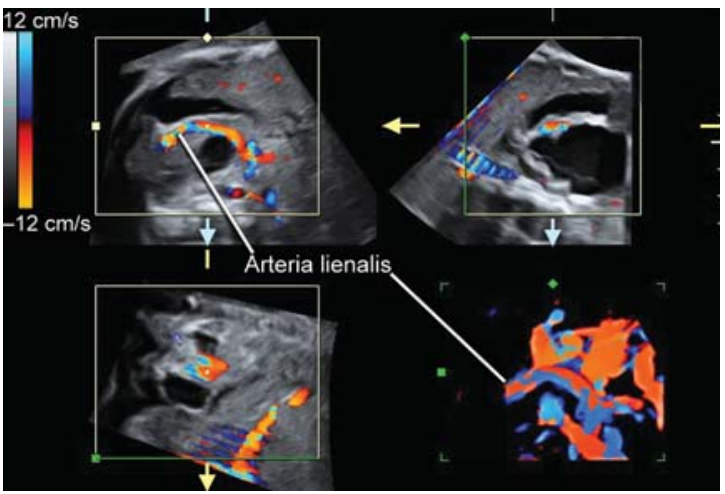

Fig. 65: Adrenal hemorrhage: 3D CD truncus coeliacus, splenic artery

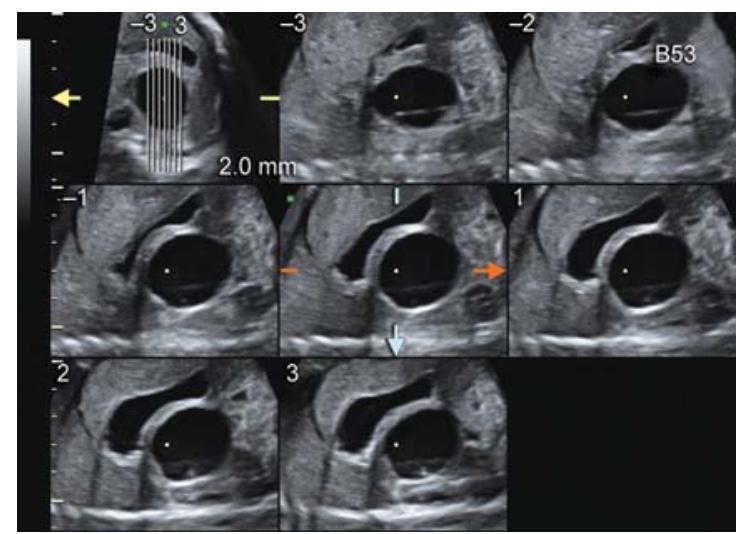

Fig. 66: Adrenal hemorrhage: Tomographic ultrasound imaging (TUI) 


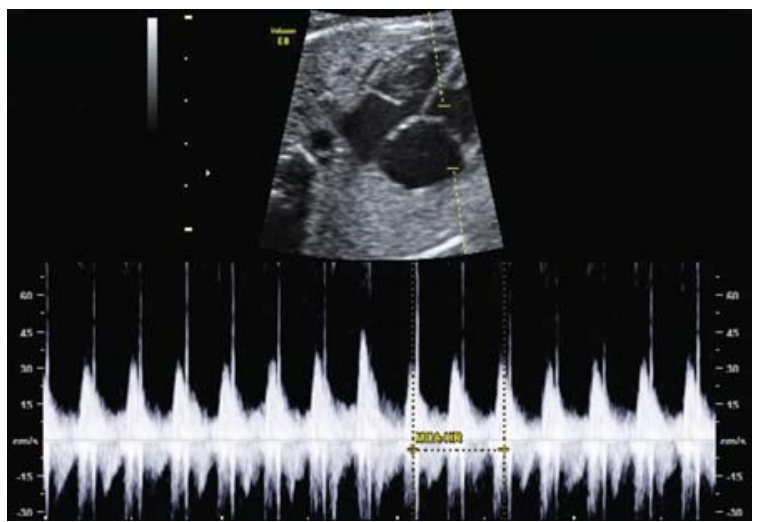

Fig. 67: Sinus tachycardia heart rate 231 beats per min (29w1d PW Doppler)

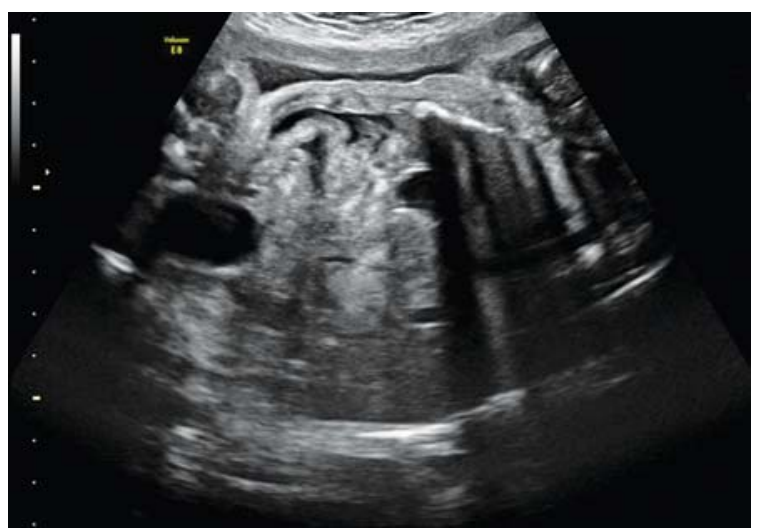

Fig. 68: Sinus tachycardia, ascites as sign of beginning forward failure

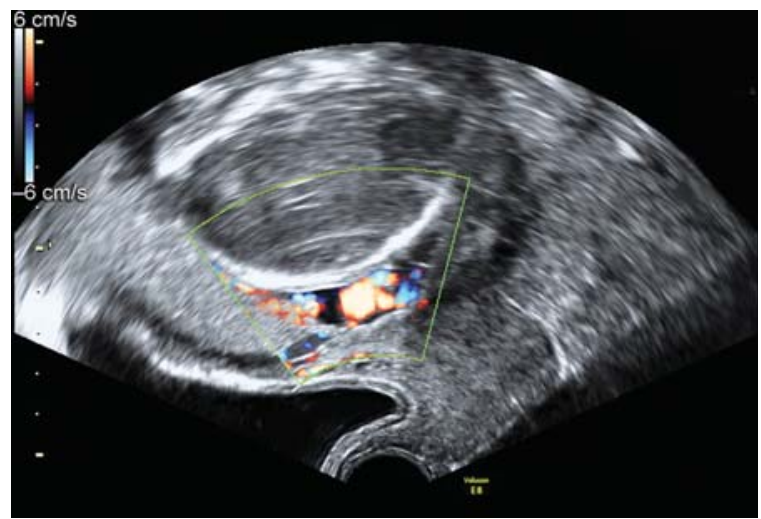

Fig. 69: Vasa previa at 23w6d, color Doppler

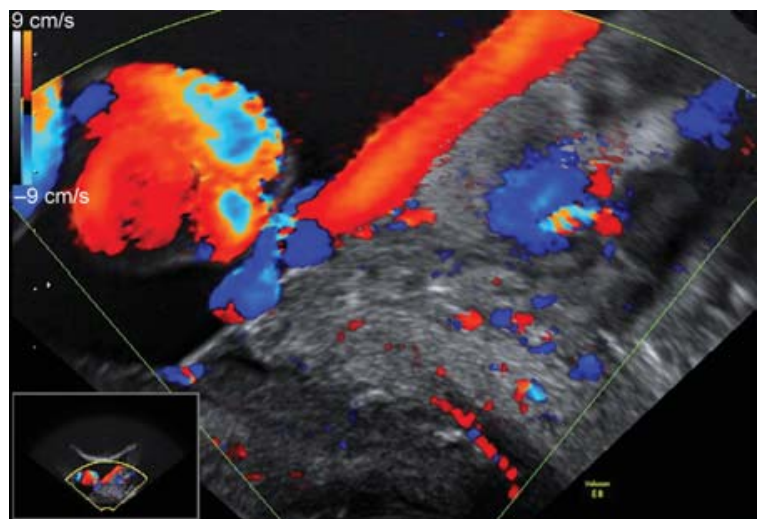

Fig. 70: Vasa previa, same fetus at $31 \mathrm{w}$, insertio velamentosa

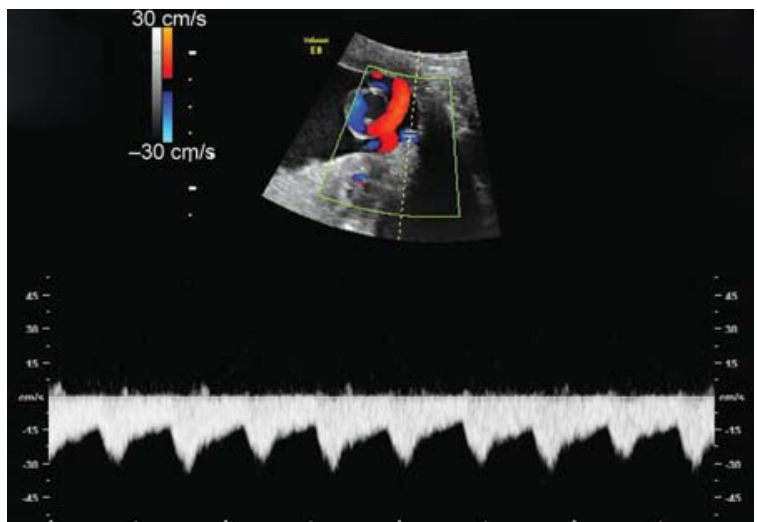

Fig. 71: Vasa previa at 31w, pulsed Doppler with fetal heart rate

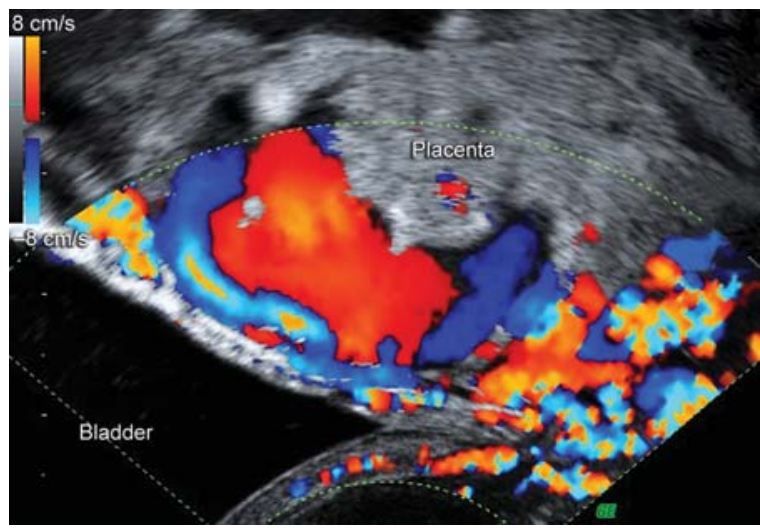

Fig. 72: Placenta previa invasiva 25w-bladder dome vascularity color Doppler

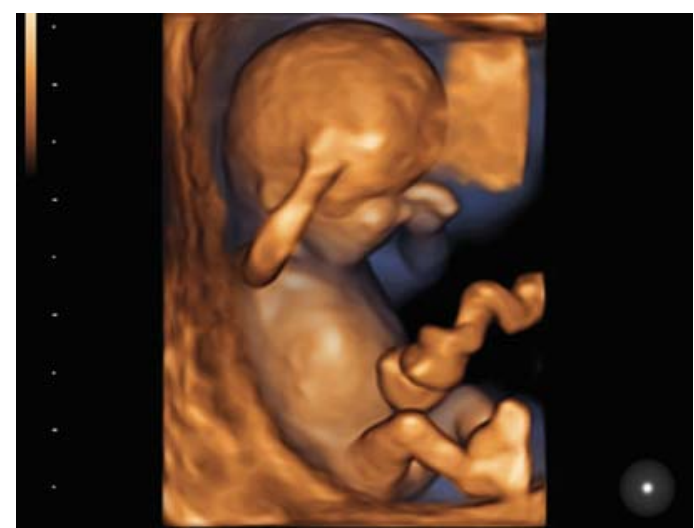

Fig. 73: Pregnancy tale continued 11w4d

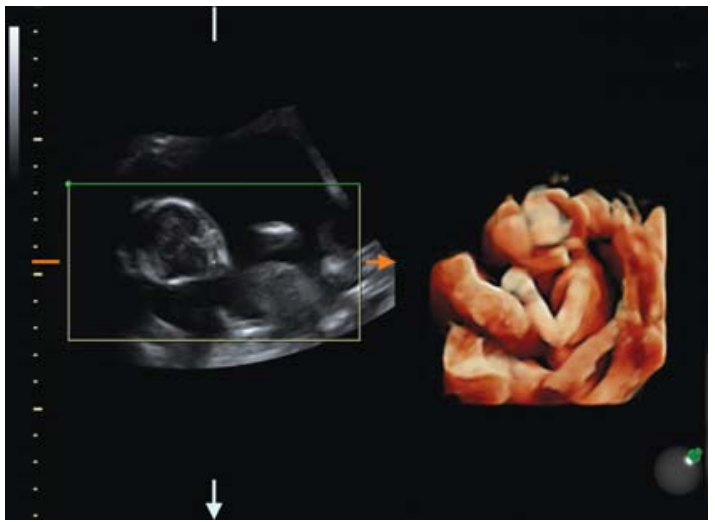

Fig. 74: Pregnancy tale continued 15w4d 


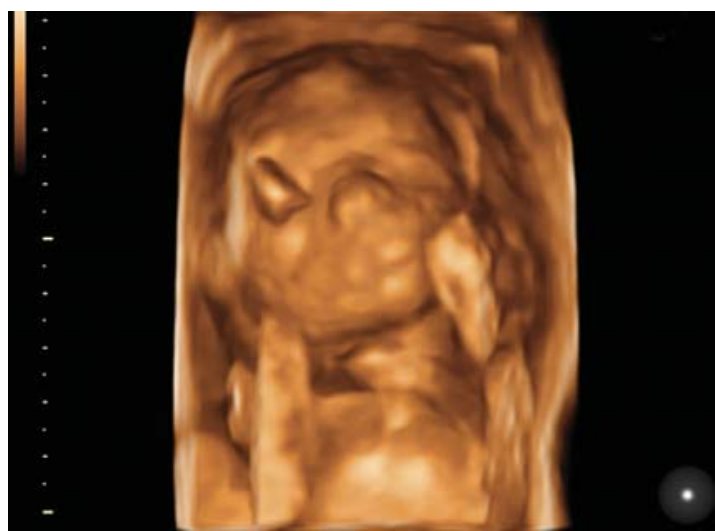

Fig. 75: Pregnancy tale continued 19w4d

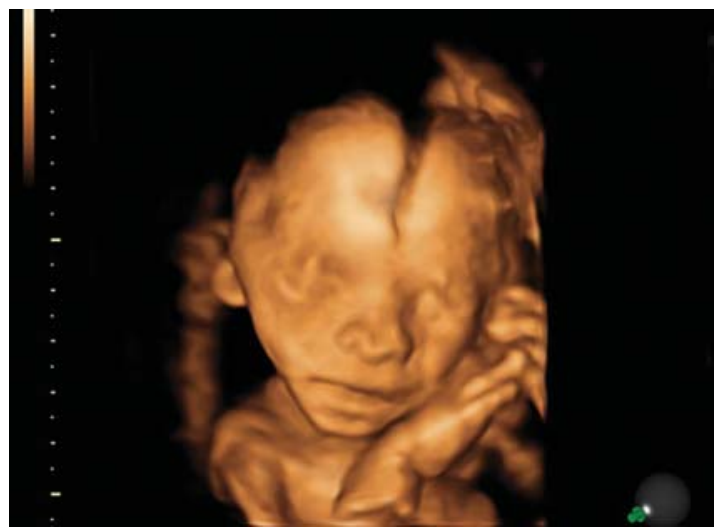

Fig. 76: Pregnancy tale continued 23w4d

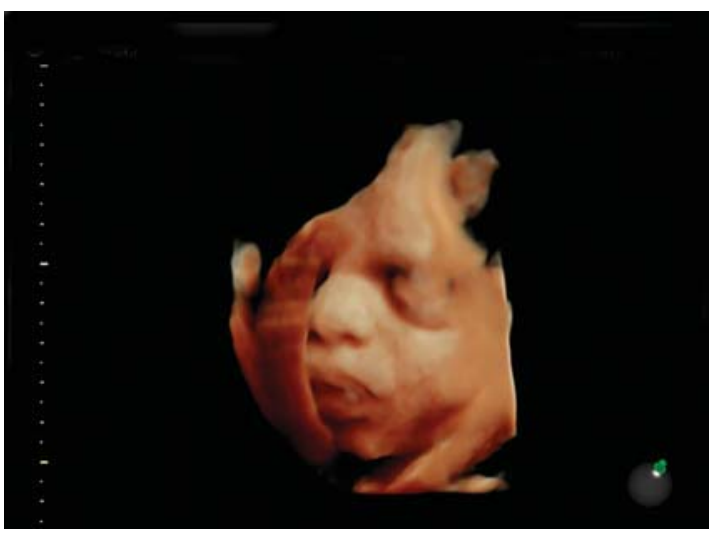

Fig. 77: Pregnancy tale continued 31w3d

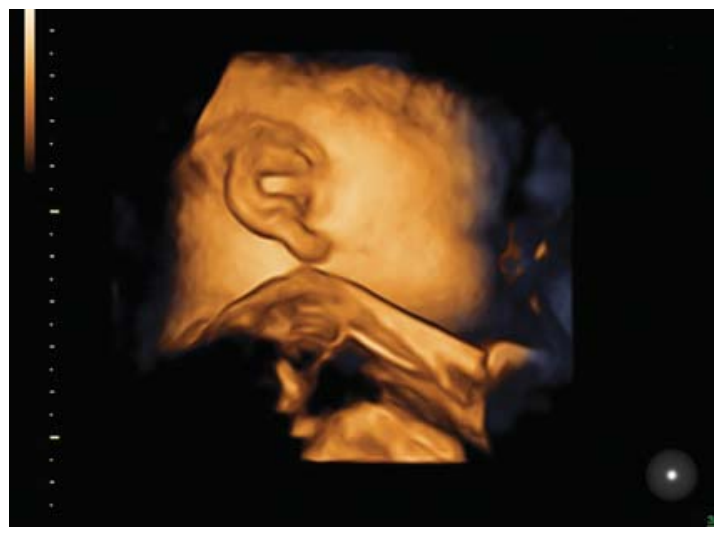

Fig. 78: Pregnancy tale continued 33w4d

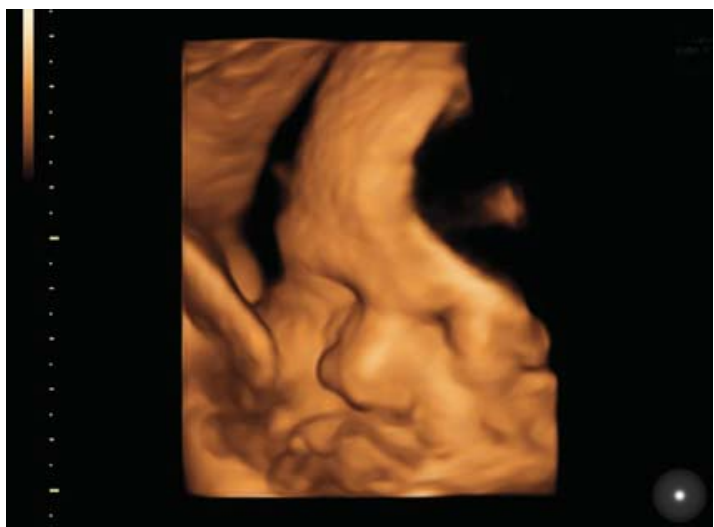

Fig. 79: Pregnancy tale continued 36w5d

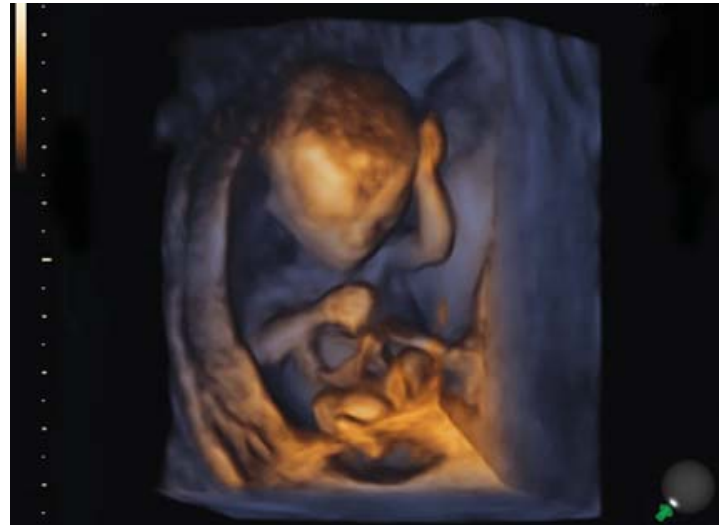

Fig. 80: 3D baby story $13 w 1 d$

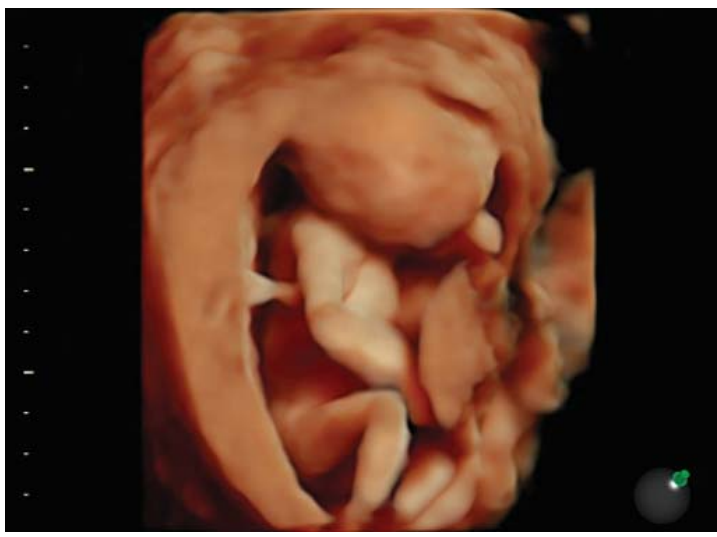

Fig. 81: 3D baby story $15 w 6 d$

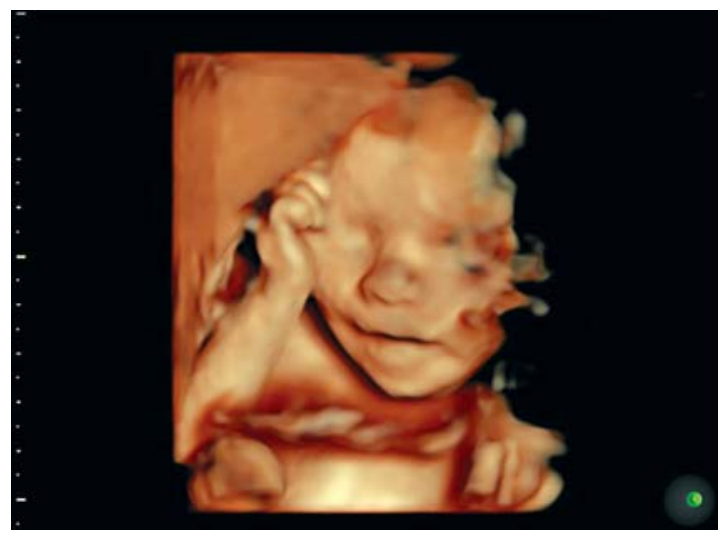

Fig. 82: 3D baby story $23 w 1 d$ 


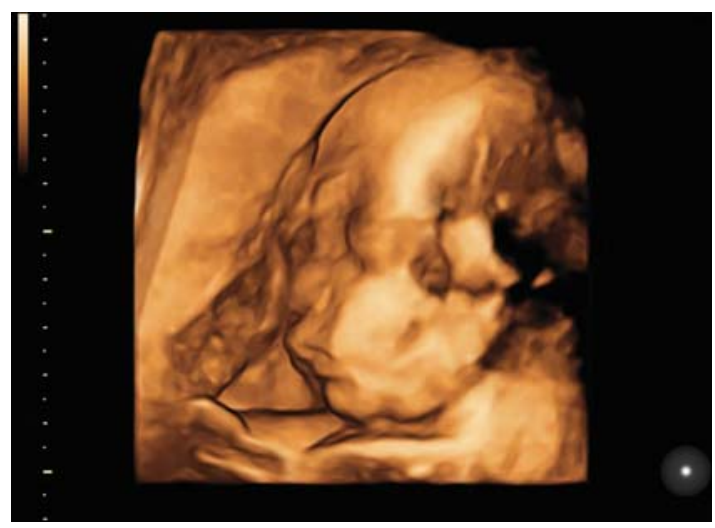

Fig. 83: $3 D$ baby story $27 w 3 d$

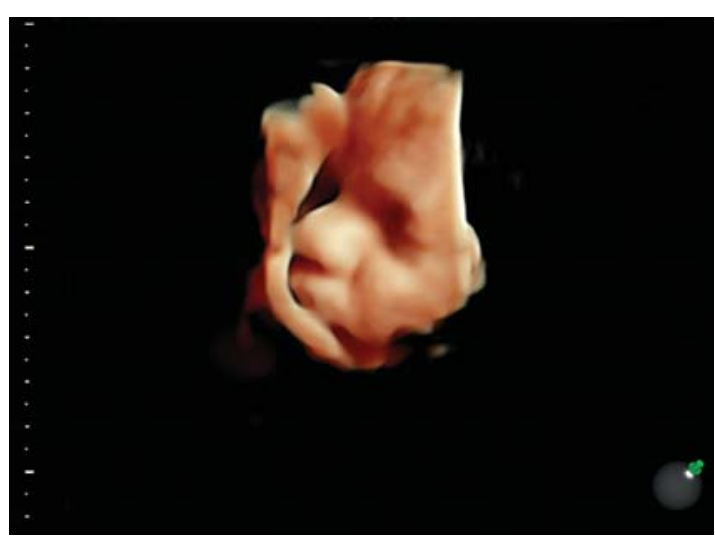

Fig. 84: 3D baby story 31 w1d

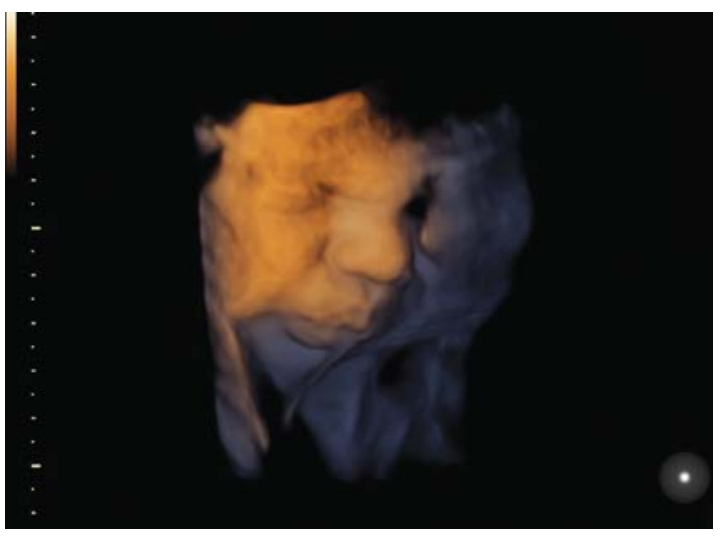

Fig. 85: 3D baby story $33 w 1 d$

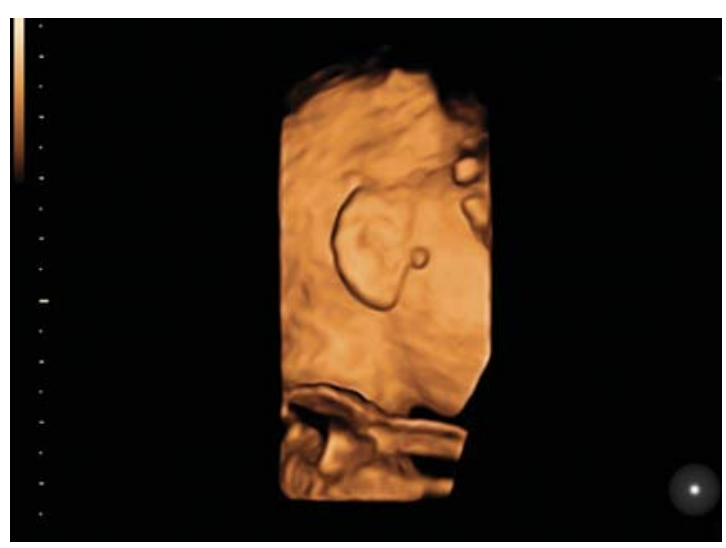

Fig. 86: Face with preauricular skin tumor movements of the head, limbs and fingers, reflecting the maturational progress of the brainstem. ${ }^{8}$

$\mathrm{H}$ and contacts with different body parts are still accidental at this time, but become goal-oriented from 18 weeks onward. ${ }^{9}$

With myelination of the spinothalamic tract and the beginning of cortical areal differentiation at 28 weeks, cortical control of fetal behavior is increasing, but the influence of the brainstem and midbrain remains predominant until well after birth. ${ }^{10}$

Hence, with fetal behavior being closely related to maturation processes of the fetal brain, al teration of behavior may indicate pathology of the CNS. W ith real-time 3D (4D), it has become possible to study and measure fetal behavior. A sim K urjak et al introduced K A NET, a neurodevel opment test based on a scoring system of quantitative and qualitative evaluation of eight biometrical and behavioral fetal parameters. ${ }^{11}$

\section{Normal and Abnormal}

Fetal Behavior Images (Figs 87 to 95)

\section{CONCLUSION}

Diagnostic ultrasound in obstetrics and gynecology can no longer be missed in clinical routine. A vailability, practicability and efficiency of ultrasound have made it an indispensable ally in the daily effort to master the challenges in our field. Often enough, the well being of high risk patients in obstetrics and gynecology depends on a competent sonographer. Uncertain findings on real-time gray scale during 2D sonography should always be reevaluated by advanced sonographic techniques. These techniques however have their own learning curve. With worldwide dissemination of practical and theoretical educational programs, recently also including online distance learning, Ian Donald School for Ultrasound, contributes exemplarily to the propagation of advanced sonographic knowledge and skills.

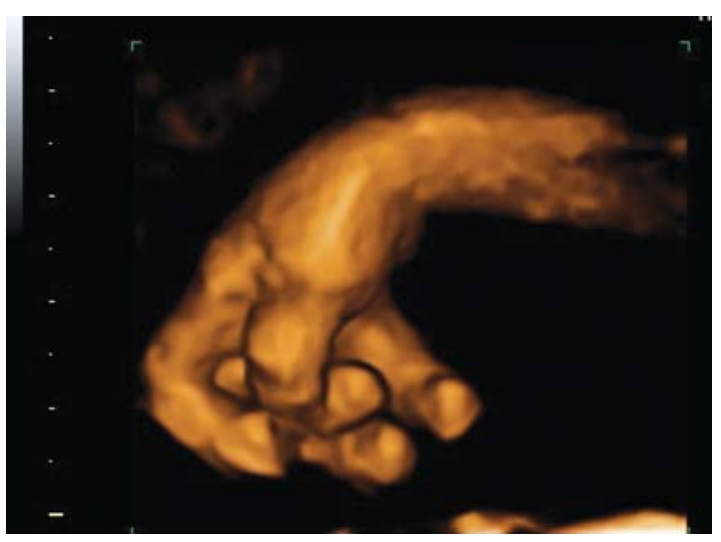

Fig. 87: Abnormal finger position at 28w4d, no flexibility of finger movements 


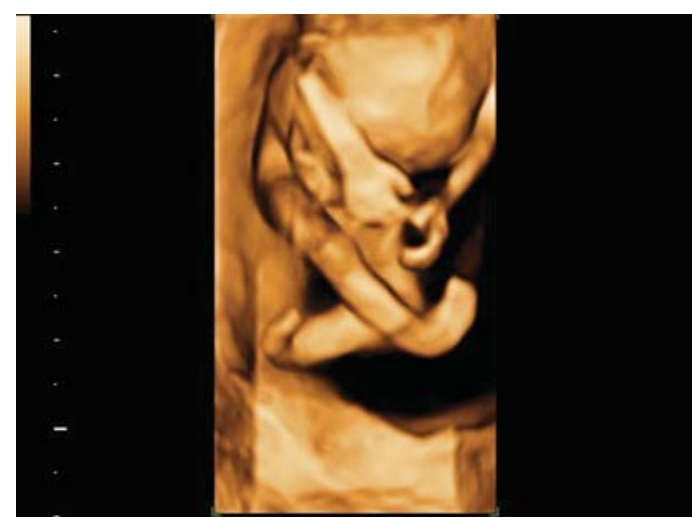

Fig. 88: Bilateral clubfeet at 14 weeks

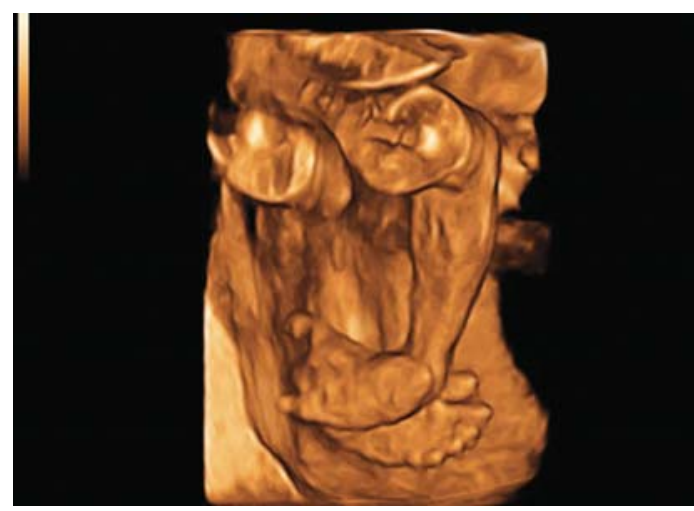

Fig. 89: Bilateral clubfeet at 22w, 3D surface mode

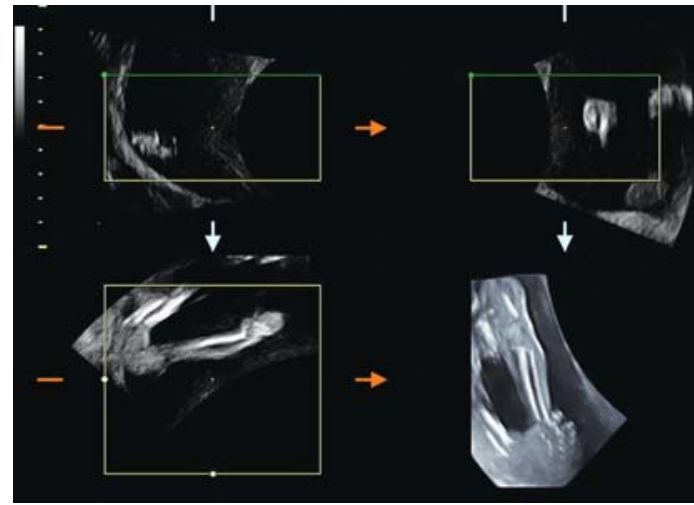

Fig. 90: Bilateral clubfeet at 22w in maximum mode

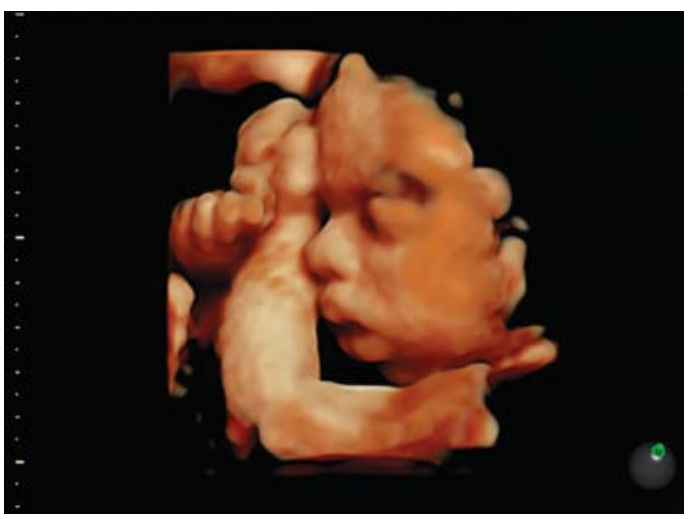

Fig. 91: Fetal akinesia with absent baseline variability 31w, repeated abnormal KANET

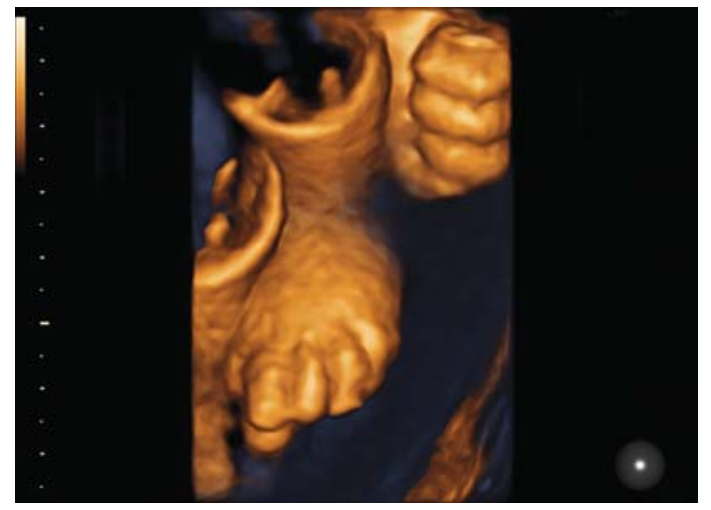

Fig. 92: Fetal akinesia with absent baseline variability $31 \mathrm{w}$ abnormal finger position, plantar flexion of dig. 1 foot

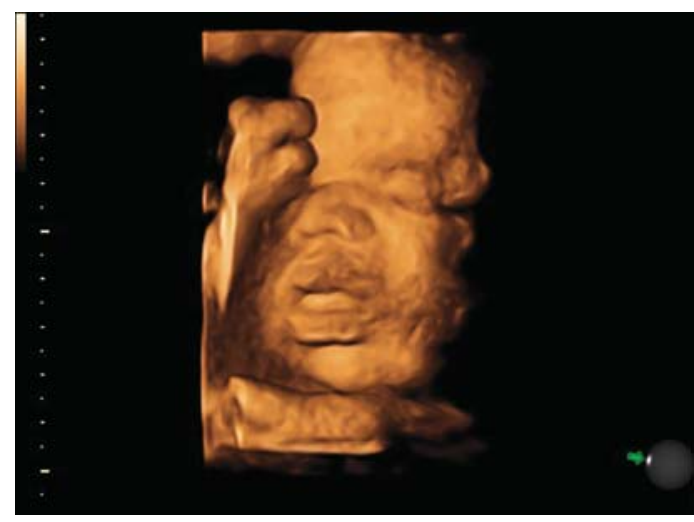

Fig. 93: Fetal akinesia at 31w, face without expression, macroglossia, and absent baseline variability in cardiotocography (CTG)

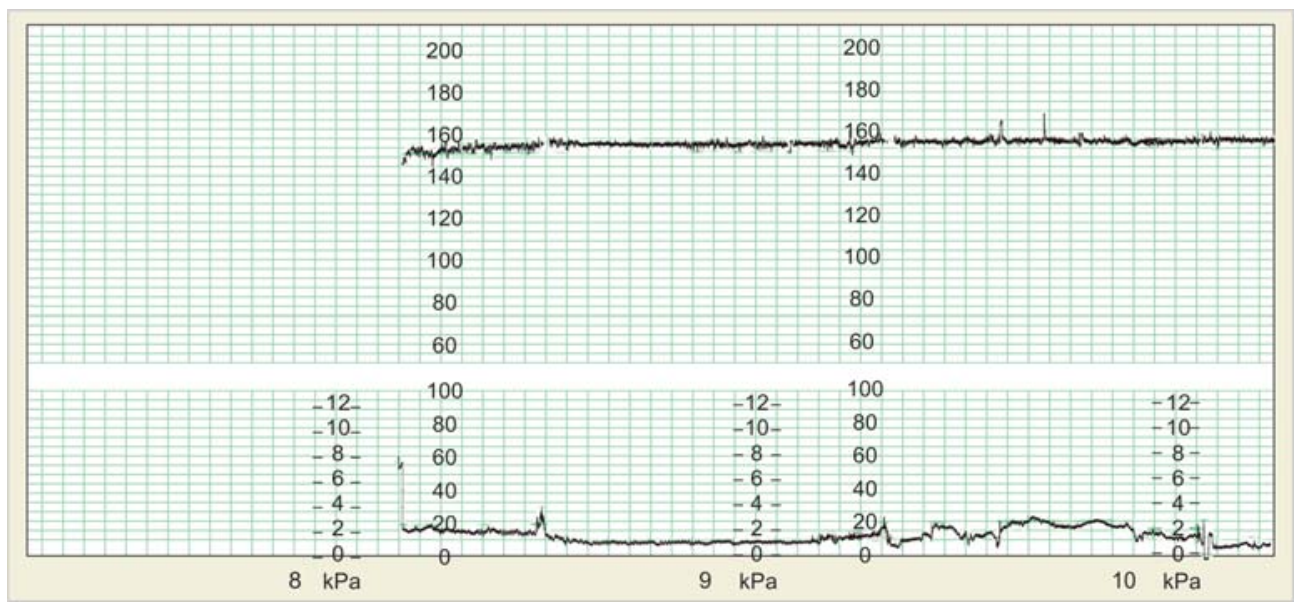

Fig. 94: Absent baseline variability in CTG as sign of severe neurological damage 


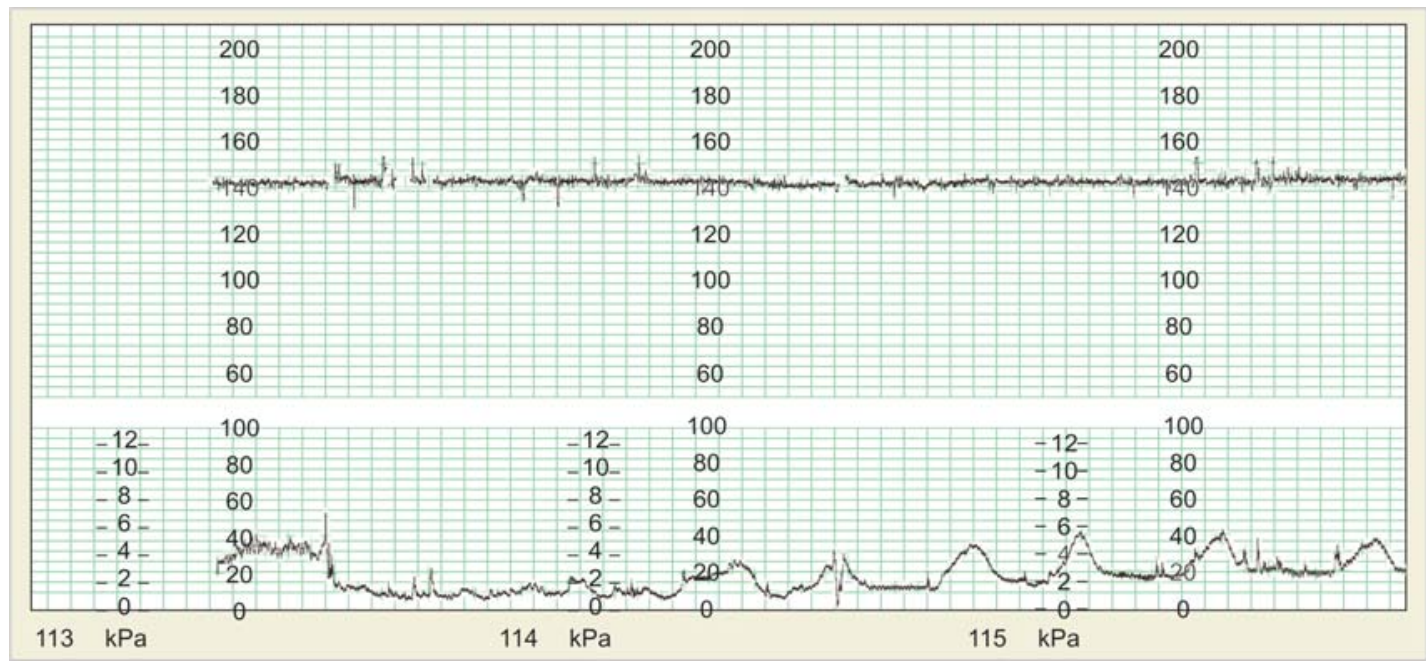

Fig. 95: Absent baseline variability persistent, abnormal KANET persistent

\section{REFERENCES}

1. Permuth-W ey J, Sellers T. Epidemiology of ovarian cancer. M ethods M ol Biol 2009;72:413-37.

2. DePriest PD, Shenson D, Fried $A$, Hunter JE, A ndrew SJ, Gallion $\mathrm{HH}$, et al. A morphology index based on sonographic findings in ovarian cancer. Gynecol Oncol 1993;51:7-11.

3. Kurjak A, Kupesic S. Transvaginal color Doppler and pelvic tumor angiogenesis: Lessons learned and future challenges. Ultrasound Obstet Gynecol 1995;6:145-59.

4. Proctor JA, Haney A F. Recurrent first trimester pregnancy loss is associated with uterine septum but not with bicornuate uterus. Fertil Steril 2003; 80:1212.

5. Kjaer I. Human prenatal craniofacial development related to brain, development under normal and pathologic conditions. A cta Odontol Scand 1995;53(3):135-43.

6. Sperber GH, Sperber SM, Guttmann GD. Craniofacial embryogenetics and development (2nd ed). USA: People's M edical Publishing House 2010.

7. Roelfsema NM, Hop W CJ, van A drichem LNA, Wladimiroff JW. Craniofacial variability index in utero: A three-dimensional ultrasound study. U Itrasound Obstet Gynecol 2007;29:258-64.

8. De V ries JI, Fong BF. Normal fetal motility: An overview. Ultrasound Obstet Gynecol 2006;27:701.
9. Zoia S, et al. Evidence of early development of action planning in the human foetus: A kinematic study. Exp Brain Res 2007;176:217-26.

10. Salihagic-K adic A, Predojevic $M$. W hat we have learned from fetal neurophysiology? DSJUOG 2012;6(2):179-88.

11. Kurjak A, M iskovic B, Stanojevic M, A miel-Tison C, A hmed $B$, A zumendi $G$, et al. New scoring system for fetal neurobehavior assessed by three- and four-dimensional sonography. J Perinat M ed 2008;36:73-81.

\section{ABOUT THE AUTHORS}

\section{Ulrich Honemeyer (Corresponding Author)}

Consultant, Department of Obstetrics and Gynecology, Welcare Hospital, AL Garhood, Dubai, UAE; Professor, Department of Perinatology, Dubrovnik International U niversity, Dubrovnik, Croatia e-mail: ulrich@welcarehospital.com

\section{Asim Kurjak}

Professor, Department of Obstetrics and Gynecology; Dean, School of M edicine, Dubrovnik International University, Croatia 